\title{
WestVirginiaUniversity
}

THE RESEARCH REPOSITORY @ WVU

Graduate Theses, Dissertations, and Problem Reports

2004

\section{Three essays on public economics and public finance}

Yousam Choi

West Virginia University

Follow this and additional works at: https://researchrepository.wvu.edu/etd

\section{Recommended Citation}

Choi, Yousam, "Three essays on public economics and public finance" (2004). Graduate Theses,

Dissertations, and Problem Reports. 2133.

https://researchrepository.wvu.edu/etd/2133

This Dissertation is protected by copyright and/or related rights. It has been brought to you by the The Research Repository @ WVU with permission from the rights-holder(s). You are free to use this Dissertation in any way that is permitted by the copyright and related rights legislation that applies to your use. For other uses you must obtain permission from the rights-holder(s) directly, unless additional rights are indicated by a Creative Commons license in the record and/ or on the work itself. This Dissertation has been accepted for inclusion in WVU Graduate Theses, Dissertations, and Problem Reports collection by an authorized administrator of The Research Repository @ WVU.

For more information, please contact researchrepository@mail.wvu.edu. 
Three Essays on Public Economics and Public Finance

\author{
Yousam Choi
}

Dissertation submitted to the

College of Business and Economics

at West Virginia University

in partial fulfillment of the requirements

for the degree of

Doctor of Philosophy

In

Economics

Santiago M. Pinto, Ph.D., Chair

Alexei V. Egorov, Ph.D.

William S. Reece, Ph.D.

Russell S. Sobel, Ph.D.

Mehmet S. Tosun, Ph.D.

Division of Economics and Finance

Morgantown, West Virginia

2004

Keywords: Collusion, Middle Class, Formula Apportionment

(c) Copyright 2004, Yousam Choi 


\title{
ABSTRACT \\ Three Essays on Public Economics and Public Finance
}

\author{
Yousam Choi
}

In the first essay, we examine the conditions under which the regulatory process leads to collusion, and if there is collusion, whether it will be observed in the political or bureaucratic sector. The political cost disciplines the politician, while monitoring intensity limits the bureaucrat's discretion. According to our model, high political pressure is critical to achieve a state with no collusion between agents. If the political cost is relatively small, higher penalties on the bureaucrat will just open the possibility of political corruption. In a politician's initiative regime, if the transfer offered to the politician in exchange for legislative effort is less than the payoffs earned by monitoring bureaucrat, political collusion does not occur. If monitoring costs are very large, the politician might decide not to control the bureaucrat, and corruption will take place in that sector. In a voter's initiative regime, a no-collusion state can be accomplished by choosing the levels of monitoring and political control appropriately.

The second essay provides an explanation to the fact that the middle class is overrepresented in the welfare state. We claim that this observation is closely related to the implicit allegiance with other social groups. The allegiance can take place between different subgroups within the middle class. This type of behavior is captured by the pooling equilibrium of the model. The middle class obtains its ideal policy if it pursues a moderate policy change from the current status quo. We show that there exists a pooling equilibrium which supports a policy change toward the ideal policy of the middle class. If the differences in political power between social groups are small, a separating equilibrium exists in which the ideal policies of the upper middle class are adopted. Such proposal is unconditionally supported by the rich, i.e. in a separating equilibrium, external allegiance is crucial.

The third essay considers a model where state governments are engaged in a strategic determination of corporate profit tax rates under different systems of formula apportionment. We show that in a symmetric equilibrium, the tax rate is inefficiently low due to the strategic interaction between state governments. However, we also show that the degree of inefficiency is less severe when the formula relies on output shares. Consequently, we can claim that the recent shift by most states in the U.S. towards a FA that employs only sales shares constitutes a welfare improvement. However, there is still a distortion due to tax competition between state governments. A cooperative formula apportionment may weaken the negative externalities created by tax competition at the local level. 


\section{Table of Contents}

Abstract

Chapter 1: A Brief Overview of the Dissertation Outline

1.1 Introduction

1.2 Overview of Dissertation

1.2.1 Collusion, Political Control and Discretion

1.2.2 Effects of Policy Preferences on Policy Outcome with an Incompletely Informed Politician

1.2.3 Apportionment Formula and Strategic Competition

Chapter 2: Collusion, Political Control and Discretion

2.1 Introduction

2.3 Analysis of collusion condition with exogenous monitoring

2.4 Collusion under politician's initiative regime

2.5 Collusion under voter's initiative regime

2.6 Conclusion

Appendix

Chapter 3: Effects of Policy Preferences on Policy Outcome with an Incompletely Informed Politician

3.1 Introduction

3.2 Model

3.3 Analysis

3.4 Conclusion

Appendix

Chapter 4: Apportionment Formula and Strategic Competition

4.1 Introduction

4.2 Model

...71

4.3 Analysis

...78

4.4 Conclusion

$\ldots 83$

Appendix

$\ldots 85$

Table 1 


\section{List of Figures and Tables}

Figure 1: Timeline of collusion $\quad \ldots 14$

Figure 2: Timeline of collusion and bureaucratic collusion $\quad \ldots 15$

Figure 3: Timeline of collusion for politician’s initiative regime $\quad$..26

Figure 4: Timeline of collusion for voter’s initiative regime $\quad \ldots 31$

Figure 5: Signaling and decision making $\quad \ldots 43$

Figure 6: Policy preference distribution $\quad \ldots 43$

Figure 7: Types of middle class and signaling $\quad \ldots 45$

Figure 8: FA policy and reaction of multistate firm $\quad \ldots 72$

Table 1: State apportionment of corporate income $\quad \ldots 89$

(Formulas for tax year 2004 -- as of January 1, 2004) 


\section{Acknowledgements}

I would like to thank Prof. Santiago Pinto for his invaluable guidance and numerous discussions over last three semesters. I have learned a lot from his expertise in the field of microeconomics and public economics. Special thanks are also due to Prof. Egorov for his encouragement and reactions for my research. I also remain indebted to Prof. Sobel, Prof. Reece, and Prof. Tosun, who introduced me to the public economics and provided many insights to support this dissertation. The remaining errors are my own. 
To my wife, Junghwa and my daughter, Sungwon 


\section{Chapter 1}

\section{A Brief Overview of the Dissertation}




\subsection{Introduction}

The three essays in this dissertation address issues in public economics and public finance. The first paper examines corruption in the political and administrative sectors, simultaneously considering interactions between firms, politicians and bureaucrats in a two-stage model. Some societies experience severe bureaucratic collusion, while political collusion is present in both developing and developed world. According to Global Corruption Barometer survey by Transparency International, 2003, “in three countries out of four, political parties are singled out as the institution from which citizens would most like to eliminate corruption in both the developed and developing worlds.” Political corruption is a serious matter even in developed countries. Our paper considers a model that highlights the main characteristics of the legislative and executive process followed in many nations. There is typically a stage at which the general law is designed, and next, there is a second stage at which the law is actually implemented. Considering the conclusions of the previously mentioned report, and the two-stage policy process, we examine the trade-off between political and bureaucratic collusion, and explore the conditions under which the regulatory process leads to collusion. We conjecture that lower bureaucratic corruption in the developed world could be consistent with a highly corrupted political process.

In the second essay, we examine the overrepresentation of the middle class in the welfare state, by using a standard signaling model. According to Director's Law, "public expenditures are made for the primary benefit of the middle class and financed with taxes which are borne in considerable part by the poor and rich” (Stigler 1970). The fact that the middle class is the main beneficiary of redistributive policies is not limited to the 
western world. Middle class bias is pervasive phenomenon. “Director’s Law” is consistent with the standard median voter theorem. However, our paper stresses that the middle class overrepresentation in the welfare state is deeply related to the implicit allegiance with other social groups. The internal allegiances within the middle class have not been addressed before. Suppose that the middle class is composed of two sub-classes: a lower and an upper middle class. When two sub-classes send the same political message to the policymaker, the middle class obtains its ideal policy if they pursue a moderate policy change from the current status quo. We show that the middle class overrepresentation in the welfare state is a possible outcome of our model, which can be explained by an implicit allegiance with other social groups.

In the third essay, we examine a model where local governments are engaged in a strategic determination of corporate profit tax rates under different systems of formula apportionment. In an effort to encourage tax uniformity, the Multi-state Tax Compact in 1967 established that the three factors considered in the apportionment formula are to be weighted equally. In spite of the compact, most states have recently deviated from the uniform formula apportionment and moved towards a greater weight on the sales portion of the corporate income tax. The apportionment of a firm's total profits across states creates complicated incentive effects. Due to the strategic interaction between state governments, the equilibrium tax rates are inefficiently low. The present paper extends the formula apportionment literature by considering the effects of different formulas on the equilibrium tax rate and the provision of local goods.

\subsection{Overview of Dissertation}

\subsubsection{Collusion, Political Control and Discretion}


In this paper, we study the conditions under which the regulatory policy process leads to collusion. We highlight the opportunities for collusion and interactions among the agents involved at different stages of the regulatory policy process. Asymmetry in the distribution of power and information allow the politician and the bureaucrat to act discretionally. The politician can change the regulation itself, favoring the firm, while the bureaucrat can favor the firm by relaxing the implementation of the regulatory rules. Given the firm's preference for no regulation and the discretionary power of the regulator, the possibility of collusion occurs. Current literature on corruption has concentrated mainly on the transaction between the firm and the bureaucrat at the implementation stage, or the relationship and interactions between interest groups and the politician. This dichotomy prevents a comprehensive understanding of bureaucratic and political corruption which, in reality, are very closely related. Our two-stage model captures the whole process of policy making and implementation and sheds new insights on corruption in the political and administrative sector.

In our model, control of the politician's behavior will have an impact on the bureaucrat. The interaction between the politician and the bureaucrat is mediated by the firm who pursues an advantageous treatment. According to our model, bureaucratic and political collusion are deeply interconnected in the sense that they can be viewed are substitutes. We stress that no bureaucratic collusion will be a result of political collusion. This conclusion is consistent with the survey result of Transparency International (2003): "even in the developed world, political corruption is serious."

When the politician monopolizes the power to control the bureaucrat, bureaucratic collusion is simply replaced by political collusion. Since the politician seeks private 
benefits, if the cost of monitoring the bureaucrat is too high, the politician may decide not to control the bureaucrat. Finally, we examine the corruption problem when the voter has the competence to discipline both the bureaucrat and the politician. However, such a regime does not insure a no-collusion state if the monitoring cost is too high. One implication of the model is that a no-collusion state is exceptional. There are two ways to prevent political corruption. One is to discipline a politician by imposing high political pressure, and the other is to provide a rent to the politician when she successfully monitors the bureaucrat.

\subsubsection{Effects of Policy Preferences on Policy Outcome with an Incompletely Informed Politician}

The allegiance among social groups affects the outcome of the political process (Mule (2001)). This paper focuses on how the allegiance among social groups affects the outcome of the political process, in particular, in favor of the middle class. We introduce two types of allegiance: one is the internal allegiance, within the middle class, and the other is external, i.e. an allegiance with the poor or rich. To capture the external allegiance, we consider three social groups: poor, middle class, and rich. Internal allegiance is related to interactions between two subgroups within the middle class. The external allegiance is implicitly reflected through the payoffs function of an office seeking politician.

Internal allegiance within the middle class is essential to obtain a pooling equilibrium which is robust to change in the distribution of power in the society. There exists a pooling equilibrium in which the policy outcome is close to the one desired by 
the middle class. The pooling equilibrium is supported by an external allegiance as well as an internal allegiance.

A separating equilibrium may exist but it is not robust, because a separating equilibrium mainly relies on an external allegiance. Conflict of interest between subgroups within the middle class may be observed in a separating equilibrium. One interesting result related to the conflict of interest between subgroups is that as the proportion of the upper middle class increases, the lower middle class may lose its capacity to influence on the policy choice. Overrepresentation of the middle class in the welfare state is realized through both types of equilibrium; a separating equilibrium is fragile and not robust.

\subsubsection{Apportionment Formula and Strategic Competition}

If a corporation has business activities located in multiple jurisdictions, the local authority can levy a tax on income generated in that state. However, as measuring income earned within each jurisdiction presents a difficult conceptual problem, a system of formula apportionment that allocates income across states is usually adopted. Formula apportionment, as used in the U.S., asserts that the proportion of a multi-state firm’s income earned in a given state is a weighted average of the proportion of the firm's total sales, property, and payroll in that state.

The choice of the specific formula apportionment is an avenue through which tax competition between state governments occurs. The apportionment of a firm's total profits across states creates complicated incentive effects. On one hand, firms operating in different regions will react to different formulas by changing the allocation of property, sales and workers across regions. On the other hand, given that the tax policy selected by 
different state governments affects residents of other states, some kind of strategic interaction can be expected. As the EU economy becomes integrated, the issues of tax coordination and tax competition become very relevant. Hence, the experience of the US in the application of a formula apportionment system is of particular interest for the EU.

We find that the inefficiency is more severe under a formula apportionment that exclusively considers capital shares relative to one that only employs sales shares, leading to a lower level of welfare in the regions. As a result, a transition towards a formula apportionment that gives more importance to the sales proportion (which is consistent with the evidence from US) might constitute a welfare improvement for the economy as a whole.

Multistate firm's reactions to tax policies are key elements in the literature of tax competition. Under a sales share formula apportionment, capital becomes less responsive to changes in the tax policy. Negative externalities on other states are created by the strategic determination of the corporate tax rates. We show that if tax rates are determined cooperatively (i.e. as if the federal government was in charge of setting the tax rates), the degree of inefficiency will be lower. 
Chapter 2

Collusion, Political Control and Discretion 


\section{Introduction}

Democratic societies decide their rules, policies and laws through a process which generally involves two stages: the design of the law or policy, and its implementation. For instance, in the case of environmental regulation, a politician usually designs the regulatory structure, while a bureaucrat implements it. Both the choice of the specific regulatory framework and its implementation affect the value of the firm subject to the regulatory regime. As a result, the firm faces an incentive to reduce the regulatory burden imposed on her. Reducing the regulatory burden can be achieved by either capturing the politician or the bureaucrat. Hence, given that any policy goes through these two stages (i.e. policy design and implementation), corruption opportunities are always present in he spheres of the political and administrative sectors.

According to Global Corruption Barometer survey by Transparency International, 2003, "in three countries out of four, political parties are singled out as the institution from which citizens would most like to eliminate corruption in both the developed and developing worlds.” In a narrow sense, corruption is interpreted as activities of transferring bribes to a bureaucrat in exchange for an advantage for specific interests. However, as the survey by “Transparency International” implies, political corruption is still a serious matter even in developed countries.

Based on the previous observations and the two-stage policy process, we conjecture in the present paper that political corruption might be a substitute for bureaucratic corruption. According to this conjecture, a lower bureaucratic corruption in the developed world could be consistent with a highly corrupted political process. Active interest groups in democratic societies usually choose to target the legislative stage of 
policy making. We define the capturing of the politician by the interest groups as political collusion.

This paper examines the trade-off between political collusion and bureaucratic collusion. We study the conditions under which the regulatory policy process leads to collusion. We highlight the opportunities for collusion and interactions among the agents involved at different stages of the regulatory policy process. Asymmetry in the distribution of power and information allow the politician and the bureaucrat to act discretionally. The politician can change the regulation itself, favoring the firm, while the bureaucrat can favor the firm by relaxing the implementation of the regulatory rules. Given the firm's preference for no regulation and the discretionary power of the regulator, the possibility of collusion occurs. The firm can offer transfers to either the politician or the bureaucrat in exchange for a more benign regulatory scheme.

This paper is closely related to the literature on bureaucratic corruption, legislative control on bureaucracy, and lobbying games. As far as we know, the existing literature on corruption has concentrated mainly on the transaction between the firm and the bureaucrat at the implementation stage of the regulatory policy, or the relationship between interest groups and the politician. However, the two alternatives have not been simultaneously considered in a single model. We would like to fill this gap by using a simple two-stage game model.

In the second stage of the game, given the regulatory policy announced by the politician in the first stage, the firm offers a bribe to the bureaucrat. In the first stage, the politician's effort determines the probability of occurrence of two states: a regulation-free state under which pollution is allowed, and a state where pollution is prohibited. The firm 
offers a transfer to induce a higher effort from the politician and, consequently, increase the probability of the no-regulation state. The transfer may take the form of a contribution to the politician's campaign. The main objective of our model is to study the nature of collusion in this context. If colluding with the politician gives higher benefits than colluding with the bureaucrat, political collusion is realized, and vice versa.

Our model about collusion between the regulated firms, bureaucratic agencies, and politicians is related to “capture theory”, addressed by Stigler (1971) by which regulatory agencies are captured by the regulated firms. We introduce a politician as an additional target of capturing. The foundation for bureaucratic collusion is "discretion" exercised by bureaucrats. Niskanen's budget maximizing bureaucrats is transformed into bureaucrats who could favor the firm in the policy implementation in our model. (Niskanen, $(1971,1975))$ However, some scholars are skeptical whether bureaucrats can successfully escape from the politician’s control. Bureaucrats are active participants in the process of policymaking, but they are tuning their policy preferences to the legislative and executive politician’s policy preferences (Calvert et al, 1989) Informational advantages exploited by bureaucrats are mitigated by the politician’s designing agency structure. (Banks et al, 1992)

There are three areas of literature about political collusion and bureaucratic collusion. The first strand of literature studies the interaction between special interest groups and the policymaker (Grossman and Helpman (2001)). At the legislative stage, the special interest group is engaged in lobbying to obtain an advantage. In this paper, the firm assumes the role of the special interest group. We show that the incentive for the firm to interact with the politician is weakened by the presence of the bureaucratic stage. 
The second strand of the literature is related to the problem of controlling a bureaucrat, since bureaucratic discretion and expertise leads to bureaucratic corruption. A complicated regulatory framework induces collusion between a public officer and a firm at the implementation stage of the policy (Kaufmann (1998) and Eskeland et al. (1999)). More discretion due to the complexity of the rules or information asymmetry leads to higher chances of collusion. (Breton and Wintrobe (1982)). Mookherjee et al. (1994) investigate the equilibrium bribe and corruption level. They show that a stronger penalty on the bureaucrat may increase the bribe paid by the firm. According to Marjit et al. (1998), if a public officer can manipulate the detection of crime, crime can never be controlled despite a reward scheme. Even if the announced penalty on crime is very high, discretion by the public officer might lower the probability of detecting crime. This strand of the corruption literature limits itself to the issue of how to control the bureaucrat at the implementation stage. One of the ways to prevent bureaucratic corruption is to pay the bureaucrat a sufficiently high wage. Acemoglu et al. (1998) show that the social cost of preventing bureaucratic collusion using effective wages might be significant because the rent given to the bureaucrat to prevent corruption induces over-employment in the public sector, leads to under-employment in the productive private sector, and lowers the overall productivity of the society. The problem of controlling the bureaucrat is still an important ingredient in our model. But, we start from the observation that both the bureaucrat and the politician can be involved in a collusive behavior. We argue that our comprehensive approach provides a better framework for the analysis of bureaucratic corruption. 
The third line of literature is related to the interaction between the politician and the bureaucrat. The role of the politician and the bureaucrat in the decision making process is studied by Alesina et al. (2003). They consider a division of labor between politicians and bureaucrats in terms of the tasks suitable for with each other. Boadway et al. (2003) analyze the interaction between the politician and the bureaucrat under asymmetric information trying to find out how to discipline the bureaucrat to overcome information asymmetry. Boyer et al. (1999) emphasize the possibility of limiting the politician's discretion to obtain political contributions from the interest groups.

In our model, the control of the politician behavior will also have an impact on the bureaucrat. The interaction between the politician and the bureaucrat is mediated by the firm who pursues an advantageous treatment. Our attempt to develop a comprehensive understanding of collusion is closely related to Börner (2004). According to our model, bureaucratic and political collusion are deeply interconnected in the sense that they can be viewed are substitutes. We stress that no bureaucratic collusion might be a result of political collusion. This conclusion is consistent with the survey of Transparency International, 2003, "even in the developed world, political corruption is serious.” Disciplining a bureaucrat is required to realize a collusion-free society. When the politician monopolizes the power to control the bureaucrat, bureaucratic collusion is simply replaced by political collusion. Since the politician seeks private benefits, if the monitoring cost is too high, the politician may decide not to control the bureaucrat. Finally, we examine the corruption problem when the voter has the competence to discipline both the bureaucrat and the politician. However, such regime does not insure a no-collusion state, if the monitoring cost is too high. 


\section{The Model}

\subsection{Outline of the whole game}

Figure 1 presents our basic model’s timeline.

Figure 1: Timeline of collusion

\begin{tabular}{|c|c|c|c|}
\hline \multicolumn{2}{|c|}{ Policy designing } & \multicolumn{2}{c|}{ Policy implementation } \\
\hline 0 & 1 & 2 & 3 \\
\hline $\begin{array}{c}\text { Firm offers transfer } \\
\text { to politician }\end{array}$ & $\begin{array}{c}\text { Politician exerts } \\
\text { effort }\end{array}$ & $\begin{array}{c}\text { Firm offers bribe to } \\
\text { bureaucrat }\end{array}$ & Payoffs are realized \\
\hline
\end{tabular}

The regulation procedure on the firm consists of enacting a regulation statute by the politician, which is implemented by the bureaucrat. Only the politician has the authority to determine the directives of the regulation on the firm. In this case, the law determines whether pollution is allowed or prohibited. We assume the regulation clauses allowing pollution requires the effort of politician and she succeeds in the deregulation allowing pollution with some probability. We also assume that the politician is not omnipotent in her legislature activities. There exists a monotonic relationship between her effort and the possibility of allowing pollution in the regulation clauses. If politician exerts an effort $e$ to enact the clauses to allow pollution, then, the new clause is enacted with probability of $p(e)$, allowing pollution. With probability $[1-p(e)]$, in spite of politician's effort, pollution is still banned. The majority rule in the legislature, the political influence of opponent interest group and the possibility of being reelected in the campaign justifies the uncertain outcome of legislation for allowing pollution.

When pollution is allowed, the payoff of the firm is $\bar{V}$ and when pollution is banned, the payoff of the firm is $\underline{V}$. The difference, $\Delta \mathrm{V}=\bar{V}-\underline{V}$ is a positive number. This difference induces the firm to look for a way to persuade the politician to allow her 
to pollute. The effort level $e$ to be exerted is not observable to the firm. However, the firm is informed about the monotonic relationship between effort and the outcome to allow pollution through $p(e)$. The outcome of the legislature effort is verifiable. The firm offers transfers to the politician. If the politician accepts the contract and the expected payoff of the firm from it dominates her expected payoff from bribing the bureaucrat in the second stage, then the game ends.

Figure 2: political collusion and bureaucratic collusion

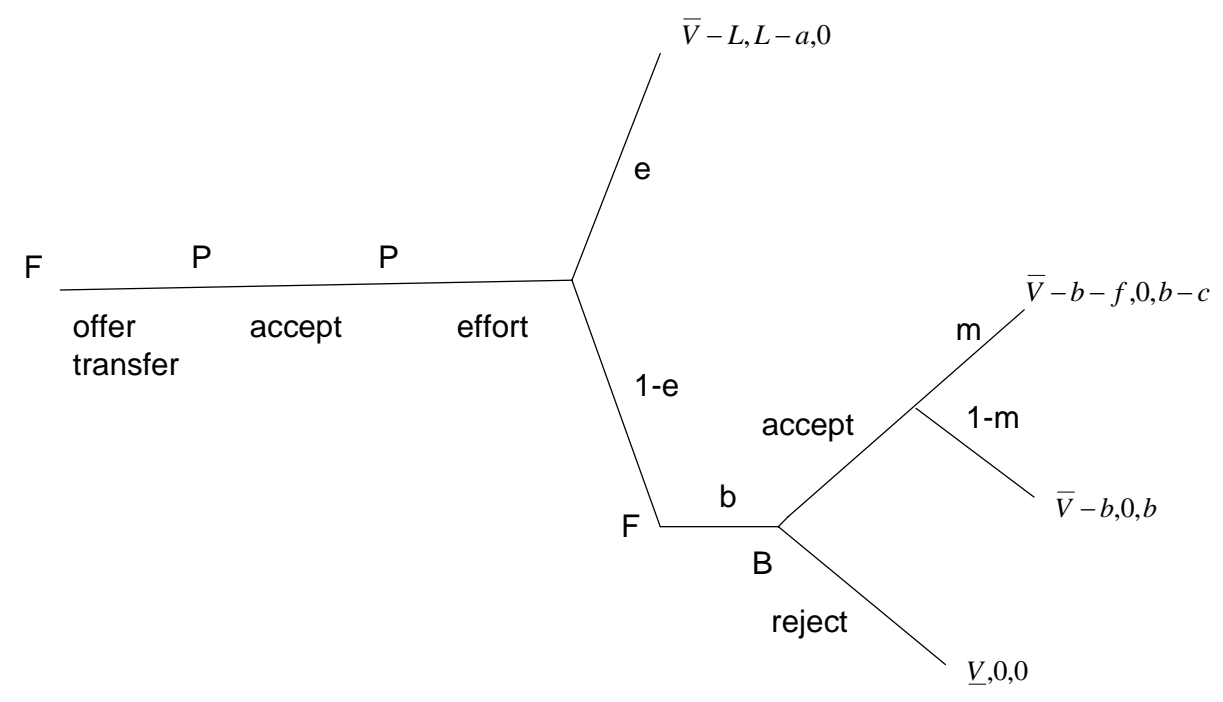

If the politician's effort to allow pollution fails and pollution is still banned, the firm deals with bureaucrat, who has the ability of weakening the regulation. Since the 
incremental benefit from polluting is $\Delta V=\bar{V}-\underline{V}$, the firm has an incentive to persuade the bureaucrat to overlook the pollution or not to report it to the authority. The firm offers the bribe $b$ to induce the bureaucrat to misreport. This constitutes the second stage of our bribing game. By using backward induction, we first solve the second stage subgame in which the bureaucrat and the firm interact with each other. The actions and the payoffs of the bureaucrat and the firm are anticipated by a rationally behaved politician and the firm in the first stage of the game. By comparing the net expected payoffs from the contract with the politician with the net expected payoff from bribing the bureaucrat, the firm finds out its best strategy.

\subsection{Second stage: equilibrium bribe when firm moves first}

If the firm decides not to pollute, the payoff is simply $\underline{V}$ and the game ends. When the firm pollutes, it obtains $\bar{V}$. The firm offers a bribe $b$ to the bureaucrat to overlook pollution, and the bureaucrat decides whether to accept or not. If the bureaucrat rejects the offer, and reports truthfully and the firm pays a fine $f$ for polluting when the law prohibits pollution. The payoff of the firm is $(\bar{V}-f)$ and bureaucrat receives a zero payoff.

Consider the case in which the bureaucrat accepts the bribe and collusion occurs between the bureaucrat and the firm. Then, the bureaucrat does not report what really happened (i.e. bureaucrat reports "no pollution”). The bureaucrat is monitored with intensity $m$, i.e. with probability $m$ misreporting is detected. When collusion is detected, a fine $f$ is imposed on the firm and a penalty $c$ is imposed on the bureaucrat. The firm's and bureaucrat's payoffs are $(\bar{V}-f-b)$ and $(b-c)$, respectively. With probability 
(1- $m$ ), collusion is not detected, so the firm and the bureaucrat obtain $(\bar{V}-b)$ and $b$.

As a result, the bureaucrat's expected payoff from colluding with the firm is

$$
m(b-c)+(1-m) b=b-m c .
$$

The bureaucrat accepts the bribe if $b-m c \geq 0$. Therefore, the equilibrium bribe in this sub-game is, ${ }^{1} b *=m c$

\section{Proposition 1 (equilibrium bribe to bureaucrat)}

When the firm moves first or has the full bargaining power, higher values of $m$ and $c$ increases the amount of the bribe that induces the bureaucrat to accept the offer.

(Mookerjee et al. 1994) $^{2}$

By plugging $b^{*}=m c$ into $(\bar{V}-b-m f)$, the expected payoff of the firm, denoted with $\beta$, is given by 11

$$
\beta=\operatorname{Max}\{\bar{V}-m(c+f), \underline{V}\}
$$

The firm compares the payoff from colluding with the bureaucrat, $\beta$ with the payoff from colluding with the politician. The payoff from colluding with the politician is explained in the next section.

\footnotetext{
${ }^{1}$ When the bureaucrat moves first or has full bargaining power, the firm accepts the offer proposed by the bureaucrat if $m(\bar{V}-b-f)+(1-m)(\bar{V}-b)>\underline{V}$. The equilibrium bribe is then given by $b=\Delta V-m f$. This amount constitutes the upper bound of bribe that the firm is willing to pay. The feasible value for bribe is $m(f+c) \leq b \leq \Delta V$. Therefore, the equilibrium bribe when the bureaucrat and the firm are engaged in a Nash Bargaining game is $b=v m c+(1-v)(\Delta V-m f)$, where $v$ is the bargaining power of the firm and (1$v$ ) is the bargaining power of the bureaucrat.

${ }^{2}$ When bureaucrat moves first, the increase in $\Delta V$ enlarges the amount of bribe and the increase in $\mathrm{f}$ and in $\mathrm{m}$ reduce the bribe. If the firm and the bureaucrat are engaged in the Nash bargaining solution, $\mathrm{m}$ enlarges the bribe only if $\mathrm{c}>\mathrm{f}$.
} 


\subsection{First-stage: interaction between politician and firm}

The outcome of the politician's effort is verifiable, while politician's effort is not. Based on the observed outcome, the firm offers the following transfer scheme: if the law allows pollution, $L_{1}$ is paid to the politician; and $L_{0}$ otherwise. We assume that there exists a monotonic relationship between the effort level exerted by the politician and the probability that the legislature outcome is "no pollution", represented by $p^{\prime}(e)>0$. In this first stage of game between the firm and the politician, the firm moves first by offering the transfers. Given $\left\{L_{1}, L_{0}\right\}$, the politician chooses her optimal effort level $e$. Anticipating the reaction of the politician, the firm chooses $\left\{L_{1}, L_{0}\right\}$ to induce an effort of politician. Regardless of which the legislature outcome is realized, the cost of effort for the politician is $\frac{d e^{2}}{2}$. For simplicity, we assume that $p(e)=e$. Suppose that the median voter prefers no pollution. The deviation from the median voter's preference is counted as a political cost, represented by $a$ when pollution is allowed. Then, the politician chooses the optimal effort $e$ that solves the following problem.

$$
\max _{\{e\}} e\left[\mathrm{~L}_{1}-\frac{d e^{2}}{2}-a\right]+(1-e)\left[\mathrm{L}_{0}-\frac{d e^{2}}{2}\right]
$$

The first order condition identifies the relationship between $e$ and the associated

transfers $\left\{L_{1}, L_{0}\right\}: e=\frac{L_{1}-L_{0}-a}{d}$. We know that $\beta$ is the payoff of the firm when it colludes with the bureaucrat if the pollution is not allowed. Let $\alpha=\bar{V}$ denote the payoff of the firm when it colludes with the politician and the pollution is allowed. The firm's expected payoffs from contributing to the politician is $e\left[\alpha-L_{1}\right]+(1-e)\left[\beta-L_{0}\right]$ and the firm's payoff from bribing the bureaucrat is $\beta$. Assuming that the individual 
rationality condition of the politician is not binding, which is verified in the appendix, the firm's problem is

$$
\max _{\left\{L_{1}, L_{2}\right\}}\left(\frac{L_{1}-L_{0}-a}{d}\right)\left[\alpha-L_{1}\right]+\left[1-\left(\frac{L_{1}-L_{0}-a}{d}\right)\right]\left[\beta-L_{0}\right]
$$

The first order condition of this problem with respect to $L_{1}$ is

$$
L_{1}-L_{0}=\frac{\alpha-\beta+a}{2}
$$

The first order condition with respect to $L_{0}$ is reduced to

$$
-(\alpha-\beta)+2\left(L_{1}-L_{0}\right)-a=-1<0
$$

Then, according to the Kuhn-Tucker conditions, $L_{0}=0$. From the first order condition with respect to $L_{1}$,

$$
L_{1}=\frac{\alpha-\beta+a}{2} .
$$

The transfer scheme offered to the politician and the effort level chosen by the politician are given respectively by $L_{1}^{*}=\frac{m(f+c)+a}{2}, L_{0}^{*}=0, e^{*}=\frac{m(f+c)-a}{2 d}$.

If net expected benefit from offering transfers to the politician at the first stage of the game exceeds the firm's payoffs from bureaucratic collusion, the firm will prefer to offer transfers $\left\{L_{1}, L_{0}\right\}$ to induce the politician to exert a higher effort level. This constitutes political collusion condition. Then, the political collusion condition is given by

$$
e\left[\alpha-L_{1}\right]+(1-e)\left[\beta-L_{0}\right]>\beta
$$


By plugging $e^{*}=\frac{m(f+c)-a}{2 d}, L_{1}^{*}=\frac{m(f+c)+a}{2}, L_{0}^{*}=0$, and $\alpha=\bar{V}, \beta=\bar{V}$ $m(f+c)$ into the political collusion condition, we obtain $2 m(f+c)>m(f+c)+a$. Then, the political collusion condition is reduced to $m(f+c)>a$.

\section{Proposition 2 (transfer to the politician)}

1. The political collusion condition is $m(f+c)>a$

2. Under the restriction of $m(f+c)>a$, the transfers $\left\{L_{1}^{*}=\frac{m(f+c)+a}{2}, L_{0}^{*}=0\right\}$ offered by the firm to the politician entails the politician's effort

$$
e^{*}=\frac{m(f+c)-a}{2 d} \text {, only political collusion occurs. }
$$

As far as the political collusion condition holds, the transfers are sufficient to induce the politician to allow pollution. The net payoff from colluding with the politician outweighs the net payoff from colluding with the bureaucrat. The implication of this proposition is that no bureaucratic collusion might be associated with political collusion.

\section{Analysis of collusion condition with exogenous monitoring}

Consider the political collusion condition: $m(f+c)>a$. LHS $m(f+c)$ is interpreted as the firm's benefit from capturing the politician, it is an expected value of the fine borne by the firm plus the penalty borne by the bureaucrat. RHS $a$ is the political cost for the politician. From $\beta=\operatorname{Max}\{\bar{V}-m(c+f), \underline{V}\}$, firm's benefit from capturing politician is associated with the cost of bureaucratic collusion. The cost of bureaucratic collusion is transformed into the benefit of political collusion. Political collusion is a substitute for 
bureaucratic collusion in our model. Suppose that $m(f+c)<a$. By offering transfers $\left\{L_{1}^{*}=\frac{m(f+c)+a}{2}, L_{0}^{*}=0\right\}$, the firm may induce the effort of $e^{*}=\frac{m(f+c)-a}{2 d}$, but capturing the politician is not valuable to the firm because the expected value of colluding with the politician is less than the expected value of colluding with the bureaucrat. Transfers to the politician are too expensive, compared with the expected benefit $m(f+c)$. The firm can achieve higher payoffs by bribing the bureaucrat in the second stage of the game. However, while $m(f+c)<a$ excludes political collusion, it does not insure bureaucratic collusion.

By the similar reasoning of political collusion condition, bureaucratic collusion condition is

$$
m(\bar{V}-b-f)+m(\bar{V}-b)>\underline{V}
$$

Since $b=m c$, this condition can be transformed into

$$
\bar{V}-m(f+c)>\underline{V} .
$$

Let $\Delta V=\bar{V}-\underline{V}$. Then, the bureaucratic collusion condition is simplified to $\Delta V>$ $m(f+c)$. Therefore, if $\Delta V<m(f+c)$, there is no bureaucratic collusion. $\Delta V$ is the benefit from bureaucratic collusion and $m(f+c)$ is the cost of bureaucratic collusion. Recall that the political collusion condition is $m(f+c)>a$. The baseline for both bureaucratic collusion and political collusion is $m(f+c)$. We mentioned that $m(f+c)$ is the firm's benefit from political collusion. However, when the bureaucrat and the firm collude, $m(f+c)$ is the expected cost. $\Delta V$ is the benefit from bureaucratic collusion. Hence, $\Delta V<m(f+c)$ precludes bureaucratic collusion. In the political sector, because 
$m(f+c)$ is the firm's benefit and $a$ is a cost, $m(f+c)<a$ also precludes the political corruption.

By combining the no collusion condition in political sector and the no collusion condition in the bureaucratic sector, we obtain the no collusion condition $\Delta V<m(f+c)$ $<a$. As a consequence, if the latter is satisfied, the pure strategy of the firm is not to bribe neither the politician nor the bureaucrat. In order to analyze all possible cases of bureaucratic and political collusion condition, consider the following two situations: (i) $\Delta V<a$, the political cost dominates the bureaucratic collusion benefit; (ii) $a<\Delta V$, the bureaucratic collusion benefit dominates the political cost.

Case (1): $\Delta V<a$

By changing the relative value of $\Delta V, a$ and $m(f+c)$, we can identify three different cases. For sufficiently low values of $m, m(f+c)<\Delta V<a$. In this case, the firm chooses to capture bureaucrat. Therefore, only bureaucratic collusion occurs in this situation. For moderate levels of $m$ such that $\Delta V<m(f+c)<a$. Because capturing the politician is too expensive, political collusion does not occur. To the politician, exerting legislature effort is too costly, due to high $a$. The bureaucratic collusion benefit $\Delta V$ is smaller than the bureaucratic collusion cost $m(f+c)$, so bureaucratic collusion is not observed. For higher levels of $m, \Delta V<a<m(f+c)$. Bureaucratic collusion is not observed, and only political collusion occurs.

Case (2): $\Delta V>a$

If $m(f+c)<a<\Delta V$, only bureaucratic collusion occurs. If $a<m(f+c)<\Delta V$, political collusion is prevented, and only bureaucratic collusion occurs. Finally, if $a<$ $\Delta V<m(f+c)$, only political collusion occurs. 


\section{Proposition 3 (no collusion condition)}

Let $\tilde{m}$ and $\hat{m}$ be defined by $a=\tilde{m}(f+c)$ and $\Delta V=\hat{m}(f+c)$.

1. Let $\Delta V<a$, given the value of $(f+c)$, monitoring intensity less than $\hat{m}$ leads to bureaucratic collusion, while monitoring intensity larger than $\tilde{m}$ leads to political collusion . No collusion is realized at moderate level of monitoring intensity between $\hat{m}$ and $\tilde{m}$.

2. Let $a<\Delta V$, at monitoring intensity less than $\hat{m}$, bureaucratic collusion occurs and at monitoring intensity larger than $\hat{m}$, political collusion occurs.

This proposition shows the importance of the political cost in achieving the no-pollution (collusion) state. If there was no political pressure, which actually discipline the politicians, collusion will always be observed. With relatively low political costs compared to bureaucratic benefit, the society has no opportunity of achieving the no pollution state. Only if $\Delta V<a$, no collusion is possible. Under the rigid regulation legislature, $\Delta V$ becomes bigger and might outweigh the political cost parameter. The firm’s incentive to avoid the regulatory burden combined with low level of political cost or low level of penalty leads to collusion which might be political or bureaucratic. According to proposition 3, monitoring intensity should be moderate to obtain no collusion state. Extreme value of monitoring intensity leads only to bureaucratic collusion or political collusion, given the penalty level on the firm and the bureaucrat who are engaged in collusion.

When $\Delta V>a$, it is not possible to obtain no collusion, because bureaucratic benefit dominates political cost. High level of $m$ without being disciplined by political pressure simply provides the opportunity for political collusion. Without sufficient 
political pressure, there only remains the possibility between political collusion and bureaucratic collusion.

Case (3): $\Delta V<a$ with $m=1$

Consider the extreme values of $m=0$ and $m=1$. With monitoring intensity $m=0$ and $\Delta V<a$, all three cases are reduced to $0<\Delta V<a$, only bureaucratic collusion occurs. Since the probability of being detected is so low, the firm is willing to collude with the bureaucrat. With monitoring intensity $m=1$ and under the parameter value of $\Delta V<a$, we again face the following three cases.

Region I: $(f+c)<\Delta V<a$ entails bureaucratic collusion

Region II: $\Delta V<(f+c)<a$ entails no collusion

Region III: $\Delta V<a<(f+c)$ entails political collusion

Case (4): $\Delta V>a$ with $m=1$

When $\Delta V>a$, with monitoring intensity $m=0$, the three cases are reduced to $0<a<$ $\Delta V$, only bureaucratic collusion occurs. With monitoring intensity $m=1$, we face the following three cases.

$$
\begin{aligned}
& \text { Region IV: }(f+c)<a<\Delta V \text { entails bureaucratic collusion } \\
& \text { Region V : } a<(f+c)<\Delta V \text { entails bureaucratic collusion } \\
& \text { Region VI: } a<\Delta V<(f+c) \text { entails political collusion }
\end{aligned}
$$

Especially, in case region I, $m=1$ cannot prevent bureaucratic collusion. Compared with the value of bureaucratic benefit $\Delta V$, the penalty term $(f+c)$ is too small. In the region $\mathrm{V},(f+c)$ is not small but $\Delta V$ is sufficiently large. With a small amount of $(f+c)$ and a large amount of $\Delta V$, perfect monitoring does not preclude collusion between the bureaucrat and the firm. Similar claim can also be argued between $a$ and $m(f+c)$. In 
the region III and region VI, perfect monitoring induces political collusion when $m=1$ is associated with medium level of political cost (region III) and low level of political cost (region VI).

\section{Proposition 4 (impact of perfect monitoring)}

1. Zero monitoring intensity leads to bureaucratic collusion, regardless of the level of political cost

2. In the region I, IV and V, perfect monitoring does not preclude bureaucratic collusion and the firm does not offer the contribution funds to the politician. In the region III and VI, perfect monitoring facilitates political collusion.

Proposition 4 examines whether penalty on the bureaucrat and fine on the firm are useful to prevent collusion. Even perfect monitoring might not work. Perfect monitoring may not prevent bureaucratic collusion when the sum of the penalty on the bureaucrat and the fine on the firm is not sufficiently high. The generous penalty leads to bureaucratic collusion, while severe penalty opens the possibility of political collusion.

Until now, we assumed that monitoring intensity $m$ is exogenous regardless of the action of a politician and a representative voter. We now investigate the change in collusion conditions when the politicians or the voter chooses the monitoring intensity $m$. We define politician's initiative regime as the regime under which the politician decides whether to monitor or not and defines voter's initiative regime as the regime under which the voter controls $m$ and $a$. Under the politician's initiative regime, she has an

additional instrument to realize her private benefit as well as the power to make an effort to allow pollution for the firm. Under the voter's initiative regime, the voter's objective is 
to exercise monitoring on bureaucrat and to impose political pressure on politician in order to prevent pollution itself.

\section{Collusion under politician's initiative regime}

Figure 3 presents our model's timeline of political collusion and bureaucratic collusion for the politician’s initiative regime.

Figure 3: Timeline of collusion for politician’s initiative regime

\begin{tabular}{|c|c|c|c|}
\hline 0 & 1 & 2 & 3 \\
\hline $\begin{array}{c}\text { Firm offers transfer } \\
\text { to Politician }\end{array}$ & $\begin{array}{c}\text { Politician exerts } \\
\text { effort }\end{array}$ & $\begin{array}{c}\text { Politician decides } \\
\text { whether to monitor } \\
\text { or not }\end{array}$ & $\begin{array}{c}\text { Firm offers bribe to } \\
\text { bureaucrat }\end{array}$ \\
\hline
\end{tabular}

This second stage of the whole game starts from the decision making of the politician whether to monitor or not. In spite of monitoring activity of the politician, the bureaucratic collusion is detected with probability $m$. The probability $m$ reflects the productivity of monitoring technology. The difference from the previous exogenous monitoring model lies in the fact that detection is possible only if the politician is determined to monitor. The firm observes the politician's decision whether to monitor or not and then, decides whether to pollute or not. After the firm is determined to pollute, it decides whether to offer bribe the bureaucrat or not. Finally, given the bribe offer by the firm, bureaucrat decides whether to accept the bribe or not.

By using backward induction, we start from the bureaucrat’s decision making. When the bureaucrat is involved in the collusion, with probability $m$, it is detected and penalty $c$ is imposed on the bureaucrat and, with probability 1- $m$, it is not detected and the bureaucrat gets full bribe. Then, the expected payoff of the bureaucrat is " $b-m c$ ". 
Then, the firm will choose the bribe $b=m c$ and the bureaucrat accepts the bribe. If the expected payoff from bribing the bureaucrat, $\bar{V}-b-m f$ is greater than the payoff $\underline{V}$ without collusion, the firm decides to pollute and bribe the bureaucrat. By anticipating the decision making of the firm and the bureaucrat to collude with each other, the politician decides to monitor when $m P$ - $k>0$, where $P$ is the prize given to the politician when the politician detects the collusion between the firm and the bureaucrat and $k$ is the cost of monitoring. If the expected value of the prize, $m P$ exceeds the monitoring cost $k$, the politician decides to monitor at the initial stage of the second subgame. Therefore, there exists a subgame perfect equilibrium in the second stage of the whole game such that the politician decides to monitor the bureaucrat, the firm decides to pollute and offers bribe to the bureaucrat, and the bureaucrat accepts the bribe.

\subsection{Prohibitive monitoring cost: $m P-k<0$}

As a trivial case, we need to consider an equilibrium in the second game when $m P-k<0$. Since monitoring is too costly, compared with the expected payoff $m P$, the politician abstains from monitoring, then bureaucratic collusion occurs. The politician's initiative regime does not insure political collusion. In this extreme case of prohibitive monitoring cost, rather it leads to bureaucratic collusion.

\subsection{Efficient monitoring technology: $m P-k>0$}

Given these equilibrium actions of bureaucratic collusion in the second stage, we examine the interaction between the politician and the firm in the first stage of the whole game. As we had done in exogenous monitoring, given transfers $\left\{L_{1}, L_{0}\right\}$ in the first tage 
of the game and expected payoff $m P$ - $k$ in the second stage of the game, the politician solves the following problem and chooses her optimal effort level $e .^{3}$

$$
\max _{\{e\}} e\left[\mathrm{~L}_{1}-a\right]+(1-e)\left[\mathrm{L}_{0}+m P-k\right]-\frac{d e^{2}}{2}
$$

Then, the optimal effort level under the politician initiative is given by

$$
e^{M}=\frac{L_{1}-L_{0}-a-(m P-k)}{d}
$$

The firm's solves the following problem and chooses the optimal $\left\{L_{1}, L_{0}\right\}$ :

$$
\max _{\left\{L_{1}, L_{2}\right\}}\left(\frac{L_{1}-L_{0}-a-(m P-k)}{d}\right)\left[\alpha-L_{1}\right]+\left[1-\left(\frac{L_{1}-L_{0}-a-(m P-k)}{d}\right)\right]\left[\beta-L_{0}\right],
$$

where $\alpha=\bar{V}$ and $\beta=\bar{V}-m(f+c)$. Then, optimal transfer under the politician initiative is given by

$$
L_{1}{ }^{M}=\frac{\alpha-\beta+a+(m P-k)}{2} \text { and } L_{0}{ }^{M}=0 .^{4}
$$

By replacing $\alpha=\bar{V}$ and $\beta=\bar{V}-m(f+c)$ into the expression,

$$
L_{1}{ }^{M}=\frac{m(f+c)+a+(m P-k)}{2} \text { and } L_{0}{ }^{M}=0 .
$$

Then, by plugging $L_{1}{ }^{M}$ and $L_{0}{ }^{M}$ into $e^{M}$, finally we obtain

$$
e^{M}=\frac{m(f+c)-a-(m P-k)}{2 d} .
$$

Under exogenous monitoring, the optimal effort was $e^{*}=\frac{m(f+c)-a}{2 d}$. Comparing with $e^{*}$, we find that the optimal effort of politician under the politician initiative, $e^{M}=$

\footnotetext{
${ }^{3}$ The additional term ( $m P-k$ ) is included in the payoff of the politician when her effort failed to change the regulation, because the politician can intervene the bureaucratic collusion by exercising monitoring.

${ }^{4}$ The first order condition with respect to $L_{0}{ }^{M}$ is reduced to $-2<0$. By Kuhn Tucker condition, $L_{0}{ }^{M}=0$.
} 
$\frac{m(f+c)-a-(m P-k)}{2 d}$ is smaller due to the presence of new term $m P-k>0$. The term $m P$ - $k$ makes $L_{1}{ }^{M}$ larger than $L_{1}{ }^{*}$, the transfer under exogenous monitoring. $m P$ $k$ changes the incentive structure of the politician to make an effort, because the politician could get a rent of $(m P-k)$ by monitoring the bureaucrat even if she does not attempt to make a legislature effort. Then, to induce a legislature effort by the politician, a higher compensation is required. This is the reasoning behind the result.

As the previous section, the political collusion condition under the politician initiative is given by

$$
e^{M}\left[\alpha-L_{1}^{M}\right]+\left(1-e^{M}\right)\left[\beta-L_{0}{ }^{M}\right]>\beta,
$$

where $\alpha=\bar{V}$ and $\beta=\bar{V}-m(f+c)$. By plugging $L_{1}{ }^{M}=\frac{m(f+c)+a+(m P-k)}{2}$, $L_{0}{ }^{M}=0$ and $e^{M}=\frac{m(f+c)-a-(m P-k)}{2 d}$, the political collusion condition is reduced to $m(f+c)>a+(m P-k)$. But, we cannot directly compare it with the prior political collusion condition, $m(f+c)>a$, since $m$ in $m(f+c)>a$ and $m^{M}$ in $m^{M}(f+c)>$ $a+\left(m^{M} P-k\right)$ might be different. To prevent the confusion, let rewrite the political collusion condition under the politician initiative as follows.

Under the restriction of $m^{M}=m$, the political collusion condition becomes stricter. However, the lowered possibility of political collusion was accompanied by the rent of ( $m P-k)$ to the politician. The rent given to the politician makes the political collusion less attractive for both the politician and the firm. Because the politician still holds the opportunity to get a rent in the second stage, the politician exerts less legislature effort. To induce the same level of legislature effort, the firm should spend higher transfer 
to persuade the reluctant politician. The higher required transfer also makes the political collusion less attractive to the firm.

Since the politician earns transfers of $L_{1}{ }^{M}=\frac{m(f+c)+a+(m P-k)}{2}$ through political collusion in the first stage of the game and the politician earns ( $m P-k)$ through monitoring in the second stage of the game, we need to check whether it is incentive compatible for the politician to accept the transfer $L_{1}{ }^{M}$ at the first stage of the game. The incentive compatible condition to take transfer is $L_{1}{ }^{M}>(m P-k)$

$$
\frac{m(f+c)+a+(m P-k)}{2}>(m P-k)
$$

is reduced to $m(f+c)>(m P-k)-a$. We know that $m(f+c)>(m P-k)+a$ is the political collusion that is incentive compatible for the firm. Because $(m P-k)+a>$ $(m P-k)-a$, when the political collusion condition for the firm is satisfied, the incentive compatible condition for the politician to take transfer is always satisfied.

The condition not to take the transfer $L_{1}{ }^{M}$ is $\frac{m(f+c)+a+(m P-k)}{2}<(m P-k)$ is reduced to $m(f+c)<(m P-k)-a$, which contradicts to $m(f+c)>(m P-k)+a$, political collusion condition in the first stage. Therefore, when the expected payoff of monitoring activity in the second stage is larger than the transfer, the political collusion does not happen.

\section{Proposition 5 (transfer to the politician)}

1. The political collusion condition in the politician's initiative regime is $m(f+c)>$ $a+(m P-k)$, which is stricter than political collusion condition $m(f+c)>a$ in exogenous monitoring. 
2. Under the restriction of $m(f+c)>a+(m P-k)$, the transfers $\left\{L_{1}^{M}=\right.$

$$
\begin{aligned}
& \left.\frac{m(f+c)+a+(m P-k)}{2}, L_{0}{ }^{M}=0\right\} \text { offered by the firm to the politician entails the } \\
& \text { politician's effort } e^{M}=\frac{m(f+c)-a-(m P-k)}{2 d} \text {, political collusion occurs. }
\end{aligned}
$$

3. With inefficient monitoring technology, the politician gives up monitoring and bureaucratic collusion occurs.

4. When transfer is not incentive compatible for the politician, $(m P-k)>L_{1}{ }^{M}$, the political collusion does not happen.

As far as the political collusion condition holds, the transfers are sufficient to induce the politician to allow pollution. But, the political collusion is not so attractive to the politician as the previous one. To induce the same level of legislature effort, higher transfers to the politician are required. With an inefficient monitoring technology, the politician gives up monitoring and bureaucratic collusion occurs. The politician's initiative regime does not insure political collusion but rather leads to bureaucratic collusion.

\section{Collusion under voter's initiative regime}

Figure 4 presents our model's timeline of political collusion and bureaucratic collusion for voter's initiative regime.

Figure 4: Timeline of collusion for voter's initiative regime

\begin{tabular}{|c|c|c|c|}
\hline 0 & 1 & 2 & 3 \\
\hline $\begin{array}{c}\text { Voter chooses monitoring } \\
\text { intensity and pressure }\end{array}$ & $\begin{array}{c}\text { Firm offers } \\
\text { transfer to } \\
\text { politician }\end{array}$ & $\begin{array}{c}\text { Politician exerts } \\
\text { effort }\end{array}$ & $\begin{array}{c}\text { Firm offers bribe } \\
\text { to } \\
\text { bureaucrat }\end{array}$ \\
\hline
\end{tabular}


The representative voter's pure interest in monitoring lies in preserving a clean environment. The voter does not care about the distribution of the bribe between the politician and the bureaucrat. The voter chooses monitoring intensity on the bureaucrat and political pressure on the politician at the initial stage of the game to achieve clean environment. ${ }^{5}$ The utility level for the voter from clean environment is denoted by $\bar{U}$, while the utility level of the voter from polluted environment is $\underline{U}$. The difference between $\bar{U}$ and $\underline{U}$ is $\Delta U$.

The monitoring effort of the voter incurs a cost of $C(m)$ which is convex in monitoring effort. The voter would like to minimize the cost of monitoring. To find out the optimal level of the monitoring effort, we examine no collusion condition, because no collusion means no pollution.

\subsection{Exogenous level of $a$}

From the previous discussion, we know that the no-collusion condition $\Delta V<m(f+c)$ $<a$ is satisfied when $\Delta V<a$ for the moderate level of monitoring of $m_{M} \in[\hat{m}, \tilde{m}]$.

\section{Case A: Efficient monitoring technology of $\Delta U>C(m)$}

Suppose that $\Delta U>C(m)$. Then, the voter would implement the monitoring. Because the representative voter seeks to minimize the cost of preventing pollution, it is sufficient to choose the monitoring intensity such that the no collusion condition $\Delta V<m(f+c)<a$ is satisfied. Then, the optimal monitoring intensity chosen by the voter, given $a$ is

$$
m *=\frac{\Delta V}{(f+c)}+\varepsilon
$$

\footnotetext{
${ }^{5}$ The voter's direct monitoring on the bureaucrat and pressing politician is equivalent to no agency problem between the voter and the politician, the bureaucrat. Voter has competence to prevent agency problem.
} 


\section{Case B: Prohibitive monitoring cost of $\Delta U<C(m)$}

With prohibitive monitoring cost, $\Delta U<C(m)$, the voter rationally gives up the monitoring, and $m *=0$.

\subsection{Exogenous level of $m$}

In this regime, the voters can also control the politician through political pressure activity $a$. In the section 5.1, we have derived $m^{*}=\hat{m}=\frac{\Delta V}{(f+c)}+\varepsilon$ when $\Delta V<a$ and $m *$ $=0$ when the monitoring is so costly. For the outcome to be no pollution, it is sufficient for the voter to choose $a$ such that the no collusion condition is satisfied.

\section{Case A: Efficient monitoring technology of $\Delta U>P(a)$}

Since the political pressure incurs a cost of $P(a)$, the voter also seeks to minimize the cost of preventing pollution. By plugging $\hat{m}=\frac{\Delta V}{(f+c)}+\varepsilon$ into the no collusion condition, we verify that no collusion condition $\Delta V<\left[\frac{\Delta V}{(f+c)}+\varepsilon\right](f+c)<a$ is obtained. Then, the optimal level of $a$ is $a^{*}=\Delta V+\varepsilon$.

$\Delta U>P(a)$

\section{Case B: Prohibitive monitoring cost of $\Delta U<P(a)$}

With prohibitive cost of political pressure, $\Delta U<P(a)$, the optimal level of $a$ is $a^{*}=0$.

\section{Proposition 6 (optimal control by voters)}

Under the perfect control by the representative voter on the bureaucrat and the politician, the optimal control level consists of $m^{*}=\frac{\Delta V}{(f+c)}+\varepsilon$ and $a^{*}=\Delta V+\varepsilon$ when costs of exerting political pressure on the politician and monitoring on the bureaucrat are low. 
But, with prohibitive monitoring cost on the politician and the bureaucrat, political pressure $m *=0$ and $a^{*}=0$.

We cannot exclude the possibility of collusion under the voter's initiative regime. With costly political pressure and monitoring, the optimal level of $a$ and $m$ becomes zero, returning back to the situation of bureaucratic collusion or political collusion as we have analyzed before.

\section{Conclusion}

In this paper, we examine the conditions under which corruption is observed either at the bureaucratic or legislative level. When the political cost is high enough and monitoring is very effective, a no-collusion state is likely to be achieved because the high political cost disciplines the politician and the efficient monitoring precludes the bureaucrat's from receiving the bribe from the firm. However, when the political cost is low, high monitoring only disciplines the bureaucrat, which opens an opportunity for the politician and firm to collude with each other. When bureaucrat benefit is high, perfect monitoring might not prevent bureaucratic collusion. According to our model, the political cost parameter plays a critical role in preventing collusion as well as does monitoring intensity.

In a politician's initiative regime, the politician decides to monitor bureaucrat or not. The politician exerts a legislature effort if the transfer to the politician in the first stage of the game outweighs the expected payoffs through monitoring in the second stage of the game. If the transfer to the politician in the first stage of the game is smaller than the expected payoffs in the second stage of the game, the 
politician never colludes with the firm in the first stage of the game. No political collusion is achieved with a social cost of rents given to the politician. With a prohibitive monitoring cost, the politician gives up monitoring, leading to bureaucratic collusion. In a voter's initiative regime, the voter decides the level of monitoring on bureaucrats and pressures on politician. No collusion can be obtained by choosing the level of monitoring and political control which are related to the level of deregulation benefits. Even, in this regime, we cannot exclude the possibility of collusion. With a prohibitive monitoring cost and political pressure cost, the optimal level of political pressure and monitoring on bureaucrat becomes zero, returning back to the situation of bureaucratic collusion or political collusion. No collusion state is an exceptional social phenomenon according to our two stages model. The two stages model captures the whole process of policy making and its implementation and sheds new insight on corruption in politics and an administrative sector. 


\section{Appendix}

Proof: The individual rationality condition for the politician is not binding.

We assumed that individual rationality condition of politician is not binding at the

equilibrium. This needs to be verified. By plugging $e^{*}=\frac{\alpha-\beta-a}{2 d}$ into politician

objective function, $e\left[\mathrm{~L}_{1}-\frac{d e^{2}}{2}-a\right]+(1-e)\left[\mathrm{L}_{0}-\frac{d e^{2}}{2}\right]$, we get

$\left(\frac{\alpha-\beta-a}{2 d}\right)\left[\left(\frac{\alpha-\beta-a}{2 d}\right)+a-\frac{d}{2}\left(\frac{\alpha-\beta-a}{2 d}\right)^{2}\right]+\left[1-\left(\frac{\alpha-\beta-a}{2 d}\right)\right]\left[-\frac{d}{2}\left(\frac{\alpha-\beta-a}{2 d}\right)^{2}\right]$

$=\frac{(\alpha-\beta-a)^{2}}{8 d}>0$. Individual rationality condition of politician is not binding at

$e^{*}=\frac{\alpha-\beta-a}{2 d}$ 


\section{Chapter 3}

\section{Effects of Policy Preferences on Policy Outcome with an Incompletely Informed Politician}




\section{Introduction}

According to Director's Law, "public expenditures are made for the primary benefit of the middle class and financed with taxes which are borne in considerable part by the poor and rich” (Stigler (1970)). The coverage of social welfare programs targeted to low income individuals has been expanded to the middle class. Compulsory education, health insurance, provision of comprehensive pension schemes, and compensation for the unemployed as a social insurance, are examples of policies that end up benefiting the middle class. Stigler (1970) suggests that this can be explained by the fact that the middle class formed an alliance with the rich in the nineteen century, while in the twentieth century they formed a coalition with the poor. The overrepresentation of the middle class as the main beneficiaries of the redistributive policies is not limited to the western world. In Japan, "social insurance constitutes the core of its policies and the middle class has gradually come to enjoy substantial benefits, giving rise to the idea of the welfare state for the middle class. The middle class, therefore, is becoming both the beneficiary of the welfare state and the backbone of welfare society” (Fujimura (2000)).

In this paper, we attempt to explain the fact that most redistributive policies are typically designed to benefit the middle class using a standard signaling model. The middle class, compared with other social groups, seems to be most dynamic sector of the society, and very flexible in terms of their political repositioning. It is typically observed that the political repositioning of the middle class shows a significant fluctuation, and the members of this group are less loyal to political parties. Preferred policies by the middle class are more volatile and sometimes ambiguous. One possible explanation is that the middle class is, in fact, divided into several subgroups and that the political message they 
send may not be consistent. This stratification within the middle class will make more difficult the observation of the true preferences by the policymaker.

According to Mule (2001), “to make sense of Director’s Law, it is sufficient to note that social groups may change their party allegiances when ruling parties actively deploy redistributive policies to manufacture electronic coalitions.” We formalize this line of reasoning in order to explain the overrepresentation of the middle class in the welfare state, and show that an office seeking policymaker may excessively target welfare policies to the middle class in a context of asymmetric information.

The conflict, coalition, and interaction between social groups have long been studied in economics, political science and sociology within various contexts. Politics is a field in which voluntary exchanges between political players occur for their own sakes and political outcomes are the results of voluntary exchanges. (Buchanan and Tullock, 1962) In this paper, we examine interplay between social groups and a policymaker seeking their own private benefits by exchanging votes with policies for special interests.

Small interests groups are "privileged" in the sense that they can avoid free rider problems which are seriously experienced by large interests groups. (Olson, 1971) A middle class is a large group which is vulnerable to the free rider problem. Moreover, a middle class as a whole is atomized and scattered, not organized as well. In this sense, Olson' arguments are in the opposite side of this paper. Despite of the handicaps a large groups may face, a middle class seemed to have successfully benefited from welfare state programs. Politician’s effort to buy more supports from voters (i.e., not confined to the middle class) solves the dilemma of large groups, contrary to the explanations of Olson's work. The policy entrepreneur and an office seeking policymaker do the jobs for the 
middle class, leading to increase their probability of being reelected. In a circumstances where an office seeking policymaker and policy entrepreneurs manage the political process, an implicit allegiance between a middle class and other social groups is formed. Through this implicit allegiance, a middle class benefits from the welfare states.

A policy entrepreneur represents interests of atomized middle class members and obtains some political surplus from his activity of organizing the latent interests of the middle class. The role of a policy entrepreneur to pick up the latent desires of a social group and transmit them to the policymaker, with a profit for himself in translating interests of middle class into a political demands (Jones, P. (1978)) According to Weingast et al (1981), an economic cost borne by a whole constituent is changed into a political benefit for a specific geographical interest. Due to the political representation based on geographical constituents, the policy benefits are concentrated on the specific areas. This reasoning is extended to the special interest group politics, where benefits targeted for the special interest group may be founded on the economic costs spread over large constituents. In our paper, the benefits of social welfare program are concentrated on the middle class, funded by the poor and the rich.

The first strand of related literature concerns the study of different pressure groups and their influence in the decision making process through voting, campaign contributions, and the endorsement of certain candidates. Part of the lobbying game literature considers an information problem between interest groups and policymakers. They conclude that the interest groups can use their private information to affect the policy outcome on their favor (Grossman and Helpman (2001), Lohmann (1995), AustenSmith (1993, 1998), Potters and Van Winden (1992), Sloof and Van Winden (2000)). We 
apply the framework of lobbying games under informational asymmetry to the problem of policy determination when there is a conflict between the objectives of different income groups.

When the policy preference of the middle class coincides with the median voters, the middle class achieves its ideal policy under majority voting rule. (Downs,1957) Parties platforms reflects the middle class preference at the expense of the rich and the poor (Dixit et al, (1998)) The median voter theorem provides an explanation of the Director's Law. Our results in this paper are quite similar with the median voter theorem. But in this paper, we follow a different approach: focusing on how the allegiance among social groups affects the outcome of the political process. The allegiance among social groups is implicitly mediated by an office seeking policymaker who is not affected by ideological considerations. We show that there exists a conflict of interest between the subgroups within the middle class and that a political outcome that may not be preferred by median voters can be realized through the implicit formation of internal and external allegiance.

Gavious et al (2003), Dhami (2003), Lohmann (1993) also consider a political equilibrium model under information asymmetry using a signaling approach. However, our emphasis is on the pooling equilibrium of the model because we think that it can explain the bias of the policies toward the middle class. In this equilibrium, both types of middle class send the same political message.

Following the claims by Stigler and Mule on the importance of political groups in explaining the overrepresentation of the middle class in the welfare state, we introduce two types of allegiance: one is the internal allegiance, within the middle class, and the 
other is external, i.e. an allegiance with the poor or rich. To capture the external allegiance, we consider three social groups: high income class (the rich), low income class (the poor) and middle class. The internal allegiance is modeled by assuming that the middle class is divided into two subgroups: upper middle class and lower middle class. The middle class policy proposal is mediated by policy entrepreneurs. The policymaker only cares about reelection.

This is an important assumption because the preferences of the social groups and their political power are mechanically translated into an objective function which drives the behavior of the office seeking policymaker. The policymaker receives the message sent by the policy entrepreneur of the middle class and chooses her action to minimize the associated political cost. Through the policymaker objective function, the middle class induces an implicit political support from other social groups.

We show that the middle class overrepresentation in the welfare state is a possible outcome of our model, which can be explained by an implicit allegiance with other social groups. The internal allegiance within the middle class is essential to obtain a pooling equilibrium which is robust to the change in the distribution of power in the society. We show that there exists a pooling equilibrium in which the policy outcome is close to the one desired by the middle class. We explain why a separating equilibrium is not robust and argue that it is not attractive for the middle class as a whole. In addition, we elucidate the conflict of interest between subgroups within the middle class in a separating equilibrium. 


\section{Model}

Figure 5 presents our basic model's timeline.

Figure 5: signaling and decision making

\begin{tabular}{|c|c|c|c|}
\hline \multicolumn{2}{|c|}{ Middle class signaling stage } & \multicolumn{2}{c|}{ Policymaker decision making } \\
\hline 0 & 1 & 2 & 3 \\
\hline $\begin{array}{c}\text { Middle class } \\
\text { privately observes } \\
\text { its own type }\end{array}$ & $\begin{array}{c}\text { Middle class } \\
\text { proposes policies } \\
\text { (send a message) }\end{array}$ & $\begin{array}{c}\text { Policymaker decides } \\
\text { whether to accept or } \\
\text { reject the proposal }\end{array}$ & Payoffs are realized \\
\hline
\end{tabular}

The whole game has two stages. At the first stage, the currently adopted policy is determined by an elected incumbent policymaker. The adopted policy is observed by all players and it constitutes status quo. At the second stage of the game, the middle class privately observes its own type. The middle class sends messages (i.e. policy proposals) through the mediation of a policy entrepreneur to the incumbent policymaker. It may not be realistic for the middle class who is atomized to act collectively. It is assumed that the policy entrepreneur organizes the collective action of the middle class costlessly. The policymaker accepts or rejects the proposal. The policymaker is an office seeker and only cares about minimizing the political cost of her decision. The proportion of upper middle class and lower middle class are common knowledge.

\subsection{Policy preference and payoffs}

Figure 2 presents the distribution of ideal policies of social groups on the line $[0,1]$.

Figure 6: Policy preference distribution

0

$x_{l}$

(interventionism) 1

(non-interventionism)

$x_{h}$ is the ideal policy for the high income class (the rich), and $x_{l}$ is the ideal policy for

the low income class (the poor). $x_{h}$ and $x_{l}$ are normalized to 0 and 1 respectively. An 
economic shock generates two types of middle class, upper middle class and lower middle class. $x_{h}^{\prime}$ is the ideal policy for the upper middle class and $x_{l}^{\prime}$ is the ideal policy for the lower middle class. Then, $x_{h}=0<x_{h}^{\prime}<x_{l}^{\prime}<x_{l}=1$. Payoffs of the middle class assume a quadratic form. The ex-post payoffs for the middle class are

$$
\begin{gathered}
U^{m}\left(x, x_{S}^{\prime}, S\right)=-\left(x-x_{S}^{\prime}\right)^{2} \text {, where } S \in\{h, l\} . \\
x=x_{h}^{\prime} \text {, when the idea policy of upper middle class is adopted } \\
x=x_{l}^{\prime} \text {, when the idea policy of upper middle class is adopted } \\
x=x_{l} \text {, when both type's ideal policies are rejected }
\end{gathered}
$$

The payoffs of both types of middle class when the status quo is $x_{l}$ and $x_{h}$ are shown in the appendix. The payoffs of the social groups are reflected on the utility function of the office seeking policymaker. The function weighs the payoffs of all social groups by their corresponding relative political powers. The political power of the social groups are denoted by $M$ for the middle, $L$ for the low, and $H$ for the high income class, respectively. The ex-post payoffs for the policymaker are given by

$$
V\left(x, x_{S}^{\prime}, L, M, H\right)=-p M\left(x-x_{h}^{\prime}\right)^{2}-(1-p) M\left(x-x_{l}^{\prime}\right)^{2}-L\left(x-x_{l}\right)^{2}-H\left(x-x_{h}\right)^{2},
$$

where $p$ is the proportion of a upper middle class. The payoffs when the status quo is $x_{l}$ and $x_{h}$ are shown in the appendix. Nature determines the two types of middle class. This assumption can be justified as follows. A good shock (a higher intellectual ability, talent, opportunities, etc.) falls on a proportion $p$ of the middle class, and a bad shock falls on the other members of the middle class (with a proportion $(1-p)$ ). The following figure shows the game in extensive form. The subgroup experiencing a good shock becomes the upper middle class and vice versa for the lower middle class. 
Figure 7: Types of middle class and signaling

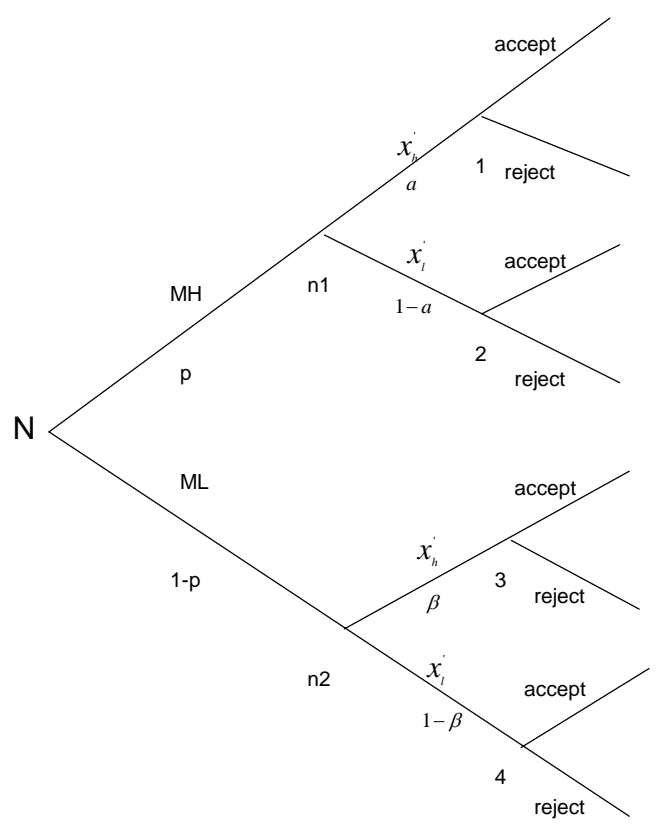

\subsection{Actions of middle class}

The upper middle class ( $\mathrm{MH})$ observes its type and sends a message (policy proposal) $x_{h}^{\prime}$ with a probability of $\alpha$ and $x_{l}^{\prime}$ with a probability of (1- $\left.\alpha\right)$ at a node of n1. The lower middle class sends a message $x_{h}^{\prime}$ with a probability of $\beta$ and $x_{l}^{\prime}$ with a probability of (1$\beta$ ) at a node of $\mathrm{n} 2$. Since the members of the middle class expect that they could be rich, the lower middle class may send a policy proposal of $x_{h}^{\prime}$ (low tax rate). They also perceive the importance of social insurance to face bad times, so the higher middle class may send a policy proposal $x_{l}^{\prime}$ (high expenditure). Due to $x_{h}=0<x_{h}^{\prime}<x_{l}^{\prime}<x_{l}=1$, the ideal policy of middle class is moderate.

\subsection{Beliefs and decision rules of a policymaker}

Since the proportion of upper middle class is $p$ (the proportion of lower middle class is 
$1-p$ ) and the upper middle class sends a signal $x_{h}^{\prime}$ with probability of $\alpha$ (the lower middle class sends a signal $x_{h}^{\prime}$ with probability of $\beta$ ), given the message of $x_{h}^{\prime}\left(x_{l}^{\prime}\right)$, the policymaker updates her posterior beliefs using Bayes rule. Then, the corresponding beliefs for each node are

$$
\begin{aligned}
& \mu_{1}=\operatorname{Pr}\left(\mathrm{MH} \mid x_{h}^{\prime}\right)=\frac{p \alpha}{p \alpha+(1-p) \beta} \text { and } \mu_{3}=\operatorname{Pr}\left(\operatorname{ML} \mid x_{h}^{\prime}\right)=\frac{(1-p) \beta}{p \alpha+(1-p) \beta} \text { for }\{1,3\} \\
& \mu_{2}=\operatorname{Pr}\left(\mathrm{MH} \mid x_{l}^{\prime}\right)=\frac{p(1-\alpha)}{p(1-\alpha)+(1-p)(1-\beta)} \text { and } \\
& \mu_{4}=\operatorname{Pr}\left(\operatorname{ML} \mid x_{l}^{\prime}\right)=\frac{(1-p)(1-\beta)}{p(1-\alpha)+(1-p)(1-\beta)} \text { for }\{2,4\}
\end{aligned}
$$

At information set $\{1,3\}$ of the policymaker, if the expected payoffs of accepting the policy proposal $x_{h}^{\prime}$ of middle income class exceeds the expected payoffs of rejecting it, then the policy proposal $x_{h}^{\prime}$ is accepted by the policymaker. Then, the decision rule (i.e. policy choice) to accept $x_{h}^{\prime}$ is described by the following acceptance condition for $x_{h}^{\prime}$.

Condition 1: when status quo is $x_{l}$, acceptance condition for $x_{h}^{\prime}$ is given by parameter values such that: $M\left[\mu_{1}\left(x_{l}-x_{h}^{\prime}\right)^{2}+\mu_{3}\left(x_{l}-x_{l}^{\prime}\right)^{2}\right]+H\left(x_{l}-x_{h}\right)^{2}>M \mu_{3}\left(x_{h}^{\prime}-x_{l}^{\prime}\right)^{2}+$ $L\left(x_{h}^{\prime}-x_{l}\right)^{2}+H\left(x_{h}^{\prime}-x_{h}\right)^{2}$.

Let call the opposite to condition 1 as “rejection condition 1". At information set $\{2,4\}$, the decision rule (i.e. policy choice) to accept $x_{l}^{\prime}$ is described by the following acceptance condition for $x_{l}^{\prime}$. 
Condition 2: when status quo is $x_{l}$, acceptance condition for $x_{l}^{\prime}$ is given by parameter values such that: $M\left[\mu_{2}\left(x_{l}-x_{h}^{\prime}\right)^{2}+\mu_{4}\left(x_{l}-x_{l}^{\prime}\right)^{2}\right]+H\left(x_{l}-x_{h}\right)^{2}>M \mu_{2}$ $\left(x_{l}^{\prime}-x_{h}^{\prime}\right)^{2}+L\left(x_{l}^{\prime}-x_{l}\right)^{2}+H\left(x_{l}^{\prime}-x_{h}\right)^{2}$.

Let call the opposite to condition 2 as “rejection condition 2”.

\subsection{Equilibrium concept}

Our objective in this paper is to examine whether there exists a political equilibrium to support the overrepresentation of the middle class. The equilibrium concept used in this model is the Perfect Bayesian Equilibrium in which the actions of the upper middle class, the lower middle class, and the policymaker are sequentially rational, and are consistent with the beliefs of the policymaker. In this model, sequential rationality is easily checked. The policymaker is an office seeker. Therefore, she accepts any policy proposal that could contribute to a reduction in political costs, given her belief about the type of middle class. (i.e., an increase in the probability of the policymaker's being reelected)

Given the office seeking policymaker's decision making, it is sufficient to check whether it is incentive compatible for both subgroups in the middle class to send messages associated with the type of equilibrium. In a pooling equilibrium, both types of middle class should have incentive to send the same messages to the policymaker. Since the current status quo policy regime is either $x_{l}$ or $x_{h}$ and the ideal policies of middle class are between these values, deviations from the status quo usually improve the welfare of the middle class.

This conclusion is especially true if the ideal policies of two types of the middle class are closely related to each other, then in a pooling equilibrium, both types send the same messages and neither is ever worse off due to a given policy change. However, in a 
separating equilibrium, there remains the possibility of a conflict of interest between the two types of middle class.

Suppose that the ideal policy of the upper middle class has been adopted by the policymaker, while the ideal policy of the lower middle class has been rejected. When $\mid x_{h}^{\prime}$ $-x_{l}^{\prime}|>| x_{l}^{\prime}-x_{l} \mid$ and the status quo is $x_{l}$, the lower middle class is worse off from the adoption of $x_{h}^{\prime}$, because adopted policy $x_{h}^{\prime}$ is too far away from the ideal policy of the lower middle class. The lower middle class, anticipating this result, may be politically passive or may actively work against any policy change in the direction of $x_{h}^{\prime}$. A separating equilibrium may not exist, since it is not incentive compatible for the lower middle class to send $x_{l}^{\prime}$ which will be rejected.

\section{Analysis}

\subsection{Signaling equilibrium when the current status quo policy favors the poor}

In this section, we examine conditions for the existence of policy equilibrium and its implication for allegiance between social groups when the status quo redistribution policy is $x_{l}$. In a pooling equilibrium, both types of middle class send the same message to the policymaker. The upper middle class and the lower middle class mimic each other, not revealing their true types (i.e. true policy preferences). In a separating equilibrium, both types of middle class send a message about their ideal policy, revealing true characteristics of the middle class. 


\section{(1) Pooling equilibrium}

Consider a pooling equilibrium in which both types of the middle class send the same political message and the corresponding optimal action of for the policymaker is \{reject $x_{h}^{\prime}$, accept $\left.x_{l}^{\prime}\right\}$. In this instance, the associated Rejection Condition 1 under a pooling strategy $\{\alpha=0, \beta=0\}$ is $H\left(x_{l}-x_{h}\right)^{2}<L\left(x_{h}^{\prime}-x_{l}\right)^{2}+H\left(x_{h}^{\prime}-x_{h}\right)^{2}$, while the associated Acceptance Condition 2 under the pooling strategy $\{\alpha=0, \beta=0\}$ is $M\left[p\left(x_{l}-x_{h}^{\prime}\right)^{2}+(1-p)\left(x_{l}-x_{l}^{\prime}\right)^{2}\right]+$ $H\left(x_{l}-x_{h}\right)^{2}>M p\left(x_{l}^{\prime}-x_{h}^{\prime}\right)^{2}+L\left(x_{l}^{\prime}-x_{l}\right)^{2}+H\left(x_{l}^{\prime}-x_{h}\right)^{2}$. Since in this type of pooling equilibrium, it is always incentive compatible for both types of the middle class to send the same signal, ${ }^{6}$ the policymaker's choice $\left\{\right.$ rejects $x_{h}^{\prime}$, accepts $\left.x_{l}^{\prime}\right\}$, a pooling strategy $\{\alpha=0, \beta=0\}$ and the outcome $\left\{x_{l}, x_{l}^{\prime}\right\}$ constitute a pooling equilibrium as in the following example.

Numerical Example 1: $\{\alpha=0, \beta=0\}$ and $\left\{\right.$ reject $x_{h}^{\prime}$, accept $\left.x_{l}^{\prime}\right\}$

$\begin{array}{ccccccccc}H & M & L & x_{l}-x_{h} & x_{l}-x_{h}^{\prime} & x_{h}^{\prime}-x_{h} & x_{l}-x_{l}^{\prime} & x_{l}^{\prime}-x_{h} & x_{l}^{\prime}-x_{h}^{\prime} \\ 1 & 0.7 & 3 & 1 & 0.7 & 0.3 & 0.4 & 0.6 & 0.3\end{array}$

Recall Rejection Condition 1, “ $H\left(x_{l}-x_{h}\right)^{2}<L\left(x_{h}^{\prime}-x_{l}\right)^{2}+H\left(x_{h}^{\prime}-x_{h}\right)^{2}$ ”, which compels the policymaker in rejecting $x_{h}^{\prime}$. LHS represents the political costs to be borne by the policymaker when she rejects the proposal, while RHS is the political costs to be borne in accepting it. Given the posterior belief, by plugging the parameter values in Numerical example 1 into "Rejection Condition 1", reduces the value " $1<1.56$ ". Since

\footnotetext{
${ }^{6}$ Since the status quo is $X_{l}$, neither the upper middle class nor the lower middle class is hurt by the policy change in the direction of $x_{l}^{\prime}$.
} 
$x_{h}^{\prime}$ is close to the ideal policy of the rich, the rich support the policy proposal $x_{h}^{\prime}$. In this circumstances, the political costs borne by a policymaker in rejecting $x_{h}^{\prime}$ are represented by the dissatisfaction of the rich (i.e., in this example, the value is 1 ). Since $L=3$ outweighs $H=1$, political costs borne by the policymaker in accepting $x_{h}^{\prime}$ (i.e., in this example, the values is 1.56) are larger than 1 . Therefore, the optimal action for the policymaker is to reject $x_{h}^{\prime}$.

Plugging the parameter values in Numerical Example 1 into "Ccondition 2", reduces the value to $1.2275>0.8715$. In this example, in which $x_{l}^{\prime}$ is not distant from $x_{l}$, the policy complaints raised by the poor are not large. The political costs to be borne when the policymaker accepts the proposal $x_{l}^{\prime}$ are not serious. (i.e., in this example, the value is 0.8715 ) Therefore, the policymaker's choice \{rejects $x_{h}^{\prime}$, accepts $x_{l}^{\prime}$ \}, given her belief, is sequentially rational. As mentioned in the previous section, since $x_{l}^{\prime}$ is always closer to ideal policies of the upper middle class, it is sequentially rational for the upper middle class to send a message of $\alpha=0$. By definition, $\beta=0$ is the best policy for the lower middle class. Actions of $\{\alpha=0, \beta=0\}$ and policy choice action of \{rejects $x_{h}^{\prime}$, accepts $\left.x_{l}^{\prime}\right\}$ are sequentially rational.

From this numerical example, we assert that there exists a pooling equilibrium in which both types of middle class send the same signal $\{\alpha=0, \beta=0\}$, the policymaker chooses $\left\{\right.$ reject $x_{h}^{\prime}$, accept $\left.x_{l}^{\prime}\right\}$, and equilibrium outcome is $\left\{x_{l}, x_{l}^{\prime}\right\}$. In spite of the weak political power of the middle class in the example $(M=1)$, the ideal policy $x_{l}^{\prime}$ of the lower middle class is adopted as a new policy. Both types of middle class is better off, 
since $x_{l}^{\prime}$ is the ideal policy of the lower middle class and $x_{l}^{\prime}$ is closer to the ideal policy of the upper middle class than the previous status quo policy was, leading to both types sending the same political message. The realized policy $x_{l}^{\prime}$ in the pooling equilibrium is not an ideal policy for the upper middle class. However, the adopted policy $x_{l}^{\prime}$ in the pooling equilibrium is better than the status quo $x_{l}$.

An interesting point of the above numerical example is that as $p$ (the proportion of the upper middle class) increases, it helps realize "Acceptance Ccondition 2". As the proportion of the upper middle class increases, the political cost of borne by the policymaker in rejecting $x_{l}^{\prime}$ also increases. This implies that there is an internal allegiance between the subgroups in middle class in the pooling equilibrium. However, this internal allegiance is caused by information asymmetry between the policymaker and the middle class (i.e., an internal allegiance with the middle class).

The political cost of rejecting $x_{l}^{\prime}$ is overestimated, due to the presence of imperfect information, which would have not been taken into account by the policymaker under circumstances of complete information. In the policy transition from the status quo $x_{l}$ to policy $x_{l}^{\prime}$, the high income class also plays an important role by supporting $x_{l}^{\prime}$ (i.e., an external allegiance with the rich).

Other things being equal, as $\left(x_{l}^{\prime}-x_{h}^{\prime}\right)$ is smaller, Acceptance Condition 2 is easily satisfied. By sending the same signal with the upper middle class, the lower middle class is the most group to benefit most from the policy change. The winners are the middle class and the rich. The losers are the low income class. 
Result 1: The pooling equilibrium $\{\alpha=0, \beta=0\}$ with a moderate policy change in the direction of $x_{l}^{\prime}$

1. There exists a pooling equilibrium to support a policy transition from $x_{l}$ to $x_{l}^{\prime}$ even if the poor hold predominant political power.

2. Internal allegiance: The policy transition in the direction of $x_{l}^{\prime}$ is unconditionally supported by the upper middle class (i.e., no conflict of interest between the subgroups within middle class). The increasing $p$ (i.e., the proportion of the upper middle class) helps to the realization of Acceptance Condition 2.

3. External allegiance: The policy transition in the direction of $x_{l}^{\prime}$ is also supported by the rich.

Rejection Condition 1 relies on two facts: The strong political power of the poor and a too high $x_{h}^{\prime}$ bias for the rich. Therefore, by introducing a moderate $x_{h}^{\prime}$ and by weakening the political power of the poor, we can generate a pooling equilibrium of $\{\alpha=1$ and $\beta$ $=1\}$. Both types send the message of $x_{h}^{\prime}$ and the policymaker accepts it. Since the political power of the poor is no longer strong, $x_{h}^{\prime}$ can be adopted as the new policy. The adopted policy $x_{h}^{\prime}$ is ideal for the upper middle class and $x_{h}^{\prime}$ is welcomed by the rich. However, if $x_{h}^{\prime}$ is too far from $x_{l}^{\prime}$, the lower middle class never sends the message $x_{h}^{\prime}$. The pooling equilibrium $\{\alpha=1$ and $\beta=1\}$ requires an internal allegiance condition.

Result 2: The pooling equilibrium $\{\alpha=1, \beta=1\}$ with a drastic policy change towards $x_{l}^{\prime}$ 
1. A pooling equilibrium of $\alpha=1$ and $\beta=1$ exist, when there are small power differences between social groups.

2. Internal allegiance: The policy transition in the direction of $x_{h}^{\prime}$ is conditionally supported by the lower middle class, only if $\left|x_{h}^{\prime}-x_{l}^{\prime}\right|<\left|x_{l}^{\prime}-x_{l}\right|$.

3. External allegiance: policy transition in the direction of $x_{h}^{\prime}$ is unconditionally supported by the rich.

(2) Separating equilibrium: $\alpha=1$ and $\beta=0$

Case 1: $\{\alpha=1, \beta=0\}$ with $\left\{\right.$ accept $x_{h}^{\prime}$ and accept $\left.x_{l}^{\prime}\right\}$

Consider the separating equilibrium in which the upper middle class sends a message of $x_{h}^{\prime}$ (i.e. $\alpha=1$ ), while the lower middle class sends a message of $x_{l}^{\prime}$ (i.e. $\beta=0$ ) and the corresponding optimal action of the policymaker is \{accept $x_{h}^{\prime}$, accept $x_{l}^{\prime}$ \}. Then, the Associated Acceptance Condition 1 under the separating strategy $\{\alpha=1, \beta=0\}$ is $M p\left(x_{l}-x_{h}^{\prime}\right)^{2}+H\left(x_{l}-x_{h}\right)^{2}-H\left(x_{h}^{\prime}-x_{h}\right)^{2}>L\left(x_{h}^{\prime}-x_{l}\right)^{2}$. The associated Acceptance Condition 2 under a separating strategy is $M(1-p)\left(x_{l}-x_{l}^{\prime}\right)^{2}+H\left(x_{l}-x_{h}\right)^{2}-$ $H\left(x_{l}^{\prime}-x_{h}\right)^{2}>L\left(x_{l}^{\prime}-x_{l}\right)^{2}$. From Condition 1 and Condition 2, it is straightforward conclusion that as $L$ becomes smaller, the possibility of $x_{h}^{\prime}$ and $x_{l}^{\prime}$ being accepted increases.

Numerical Example $2\{\alpha=1, \beta=0\}$ with $\left\{\right.$ accept $x_{h}^{\prime}$, accept $\left.x_{l}^{\prime}\right\}$

$\begin{array}{ccccccccc}H & M & L & x_{l}-x_{h} & x_{l}-x_{h}^{\prime} & x_{h}^{\prime}-x_{h} & x_{l}-x_{l}^{\prime} & x_{l}^{\prime}-x_{h} & x_{l}^{\prime}-x_{h}^{\prime} \\ 1 & 0.7 & 1.2 & 1 & 0.7 & 0.3 & 0.4 & 0.6 & 0.3\end{array}$


Given the posterior belief, plugging parameter values in Numerical Example 2 into Condition 1 , reduces the value to $1.555>0.588$. In this example, the power differences between $L$ and $H$ are negligible. In this case, the political costs of rejecting $x_{h}^{\prime}$ outweigh the political costs of accepting $x_{h}^{\prime}$. Therefore, the optimal response of the policymaker is to accept $x_{h}^{\prime}$.

Plugging parameter values in Numerical Example 2 into Condition 1, reduces the value to $1.555>0.588$. With the small power differences between social groups in this example, the political costs of rejecting $x_{l}^{\prime}$ outweighs the political costs of accepting $x_{l}^{\prime}$. In this case, the optimal response of the policymaker is to accept $x_{l}^{\prime}$. Therefore, the policymaker's choice $\left\{\right.$ accept $x_{h}^{\prime}$, accept $\left.x_{l}^{\prime}\right\}$, given her belief, is sequentially rational. Since $x_{h}^{\prime}$ and $x_{l}^{\prime}$ are ideal policies for each subgroup of the middle class, by definition. $\left\{\alpha=1\right.$ (proposing $x_{h}^{\prime}$ ), and $\beta=0$ (proposing $\left.\left.x_{l}^{\prime}\right)\right\}$ are sequentially rational.

There exists a separating equilibrium such that the policymaker's choice \{accept $x_{h}^{\prime}$, accept $\left.x_{l}^{\prime}\right\}$, the separating strategy $\{\alpha=1, \beta=0\}$ and outcome $\left\{x_{h}^{\prime}, x_{l}^{\prime}\right\}$ constitute an equilibrium. However, in order to support a separating equilibrium, it is requirement that political power differences between the social groups be negligible to support a separating equilibrium. When $L$ is highly dominant over $H$ and $M$, a separating strategy by the middle class cannot induce policy change, while a pooling strategy could invoke policy change, despite the substantial power differences among the social groups (e.g., Example 1).

If the restriction on power differences is satisfied, in spite of the relatively weak political power of the middle class, the ideal policies of both types of the middle class are 
adopted. The internal allegiance condition $\left|x_{h}^{\prime}-x_{l}^{\prime}\right|<\left|x_{l}^{\prime}-x_{l}\right|$ is not required, because two types of middle class need not cooperate with each other in sending messages. Rather, this separating equilibrium includes the possibility of conflicts of interest between the upper middle class and the lower middle class. This possibility for conflict of interests is dealt with as follows in Case 2.

Result 3: The separating equilibrium of $\{\alpha=1, \beta=0\}$ with accept $x_{h}^{\prime}$, accept $\left.x_{l}^{\prime}\right\}$

1. The existence of the separating equilibrium of $\{\alpha=1, \beta=0\}$ with \{accept $x_{h}^{\prime}$, accept $\left.x_{l}^{\prime}\right\}$ is supported by the small power differences between the social groups.

2. External allegiance: The policy transition toward $x_{h}^{\prime}$ or $x_{l}^{\prime}$ is unconditionally supported by the rich.

When the political power differences between social groups are small, each class may regard itself as decisive group in determining policies. In the separating equilibrium, the middle class may lack any incentive to have internal allegiance within the class. Since the separating equilibrium is supported by the small political power differences, the upper middle class (or the lower middle class) has an incentive to have an external allegiance with the rich (or the poor). We are looking for the possibility of these conflicts of interest within the subgroups in Case 2.

Case 2: $\{\alpha=1, \beta=0\}$ and $\left\{\right.$ accept $x_{h}^{\prime}$ and reject $\left.x_{l}^{\prime}\right\}$

According to Condition 1 and Condition 2, the implication is that as $p$ increases, the possibility of $x_{h}^{\prime}$ being adopted increases and the possibility of $x_{l}^{\prime}$ being adopted decreases. In a pooling equilibrium, the possibility of $x_{l}^{\prime}$ being adopted increased in $p$. 
With a high value of $p$, Condition 1 is easily satisfied while Condition 2 may be harder to satisfy. As $p$ increases, the political cost of rejecting $x_{l}^{\prime}$ becomes smaller. The value of $p$ affects the final decision of the policymaker and introduces different type of separating equilibrium to be discussed here.

In this type of separating equilibrium, the higher proportion of the upper middle class (i.e., a higher $p$ ) may prohibit the realization of the ideal policy for the lower middle class, since $x_{l}^{\prime}$ is easily rejected, which implies, that the remaining subgroup (1$p$ ) may be excluded from the policy setting procedure. The ideal policy for the lower middle class is rejected and only the ideal policy for the upper middle class is considered by the policymaker. In a separating equilibrium, true types of subgroups in the middle class are revealed, the policymaker cares only about the policy proposal of the politically important subgroup (i.e., the upper middle class when $p$ is high). The minority subgroup (1- $p)$ is politically segregated.

Whether the adoption of the ideal policy for the upper middle class improves the welfare of the lower middle class is uncertain. If the ideal policy for the upper middle class is closer to the ideal policy for the lower middle class, its adoption may constitute welfare improvement for the lower middle class, despite the fact that the political participation of the minority subgroup is excluded. Especially if $x_{l}^{\prime}$ is distant from $x_{h}^{\prime}$, the welfare of the lower middle class may be worse off due to the policy change towards $x_{h}^{\prime}$.

If $x_{l}^{\prime}$ is substantially distant from $x_{h}^{\prime}$, then the lower middle class and the upper middle class should be categorized as different social groups. In this case, the lower middle class would be similar to the poor. This type of separating equilibrium shows the 
existence of a conflict of interest within the middle class. In the pooling equilibrium of $\{\alpha=1, \beta=0\}$, the interests of the upper and lower middle class were aligned. In the separating equilibrium of $\{\alpha=1, \beta=0\}$ with $\left\{\right.$ accept $x_{h}^{\prime}$ and reject $\left.x_{l}^{\prime}\right\}$, as $p$ increases and $\left|x_{h}^{\prime}-x_{l}^{\prime}\right|$ becomes bigger, conflicts of interests within middle class occur.

As a concluding remark in this section, we evaluate welfare impact on the social groups under the separating equilibrium. In a separating equilibrium in Case 1 , the welfare of both types of middle class improves. In this situation, the loser is the poor. In the separating equilibrium of Case 2, the welfare of the upper middle class improves. The rich benefit from any policy change in the direction of $x_{h}^{\prime}$ in either case. If $x_{h}^{\prime}$ is distant from $x_{l}^{\prime}$, the losers are the lower middle class and the poor. In both cases, $x_{h}^{\prime}$ is chosen, which makes the rich be winners.

Result 4: The separating equilibrium $\{\alpha=1, \beta=0\}$ with $\left\{\right.$ accept $x_{h}^{\prime}$, reject $\left.x_{l}^{\prime}\right\}$

1. As the proportion of the upper middle $(p)$ increases, the probability that the ideal policy of the remaining subgroup $(1-p)$ is rejected increases.

2. Internal allegiance: as $p$ and $\left|x_{h}^{\prime}-x_{l}^{\prime}\right|$ increase, a conflict of interest occurs between the subgroups. When $\left|x_{h}^{\prime}-x_{l}^{\prime}\right|>\left|x_{l}^{\prime}-x_{l}\right|$, the lower middle class is worse off.

3. External allegiance: The policy transition toward $x_{h}^{\prime}$ is unconditionally supported by the rich. 


\subsection{Equilibrium when the status quo policy is for the rich}

In this section, we examine conditions for the existence of policy equilibrium and its implication for allegiance between social groups when the status quo redistribution policy is $x_{h}$. The corresponding acceptance conditions are as follows:

Condition 3: the acceptance condition for $x_{h}^{\prime}$ when status quo is $x_{h}$ is given by parameter values such that: $M\left[\mu_{1}\left(x_{h}-x_{h}^{\prime}\right)^{2}+\mu_{3}\left(x_{h}-x_{l}^{\prime}\right)^{2}\right]+L\left(x_{h}-x_{l}\right)^{2}$

$>M \mu_{3}\left(x_{h}^{\prime}-x_{l}^{\prime}\right)^{2}+L\left(x_{h}^{\prime}-x_{l}\right)^{2}+H\left(x_{h}^{\prime}-x_{h}\right)^{2}$. In opposition to “Condition 3," this situation is called by Rejection Condition 3.

Condition 4: The acceptance condition for $x_{l}^{\prime}$ when the status quo is $x_{h}$ is given by parameter values such that: $M\left[\mu_{2}\left(x_{h}-x_{h}^{\prime}\right)^{2}+\mu_{4}\left(x_{h}-x_{l}^{\prime}\right)^{2}\right]+L\left(x_{h}-x_{l}\right)^{2}>M \mu_{2}$ $\left(x_{l}^{\prime}-x_{h}^{\prime}\right)^{2}+L\left(x_{l}^{\prime}-x_{l}\right)^{2}+H\left(x_{l}^{\prime}-x_{h}\right)^{2}$.In opposition to "Condition 4," this situation is called by Rejection Condition 4.

\section{(1) Pooling equilibrium}

Case 1: $\alpha=1$ and $\beta=1$

When the pooling strategy $\{\alpha=1, \beta=1\}$ is chosen by the middle class, the associated Acceptance Condition 3 for $x_{h}^{\prime}$ is $M\left[p\left(x_{h}-x_{h}^{\prime}\right)^{2}+(1-p)\left(x_{h}-x_{l}^{\prime}\right)^{2}\right]+L\left(x_{h}-x_{l}\right)^{2}>$ $M p\left(x_{h}^{\prime}-x_{l}^{\prime}\right)^{2}+L\left(x_{h}^{\prime}-x_{l}\right)^{2}+H\left(x_{h}^{\prime}-x_{h}\right)^{2}$ and the associated Rejection Condition 4 for $x_{l}^{\prime}$ is $L\left(x_{h}-x_{l}\right)^{2}<L\left(x_{l}^{\prime}-x_{l}\right)^{2}+H\left(x_{l}^{\prime}-x_{h}\right)^{2}$.

Numerical Example $3 \alpha=1$ and $\beta=1$

$\begin{array}{ccccccccc}H & M & L & x_{l}-x_{h} & x_{l}-x_{h}^{\prime} & x_{h}^{\prime}-x_{h} & x_{l}-x_{l}^{\prime} & x_{l}^{\prime}-x_{h} & x_{l}^{\prime}-x_{h}^{\prime} \\ 3 & 0.5 & 1 & 1 & 0.5 & 0.5 & 0.4 & 0.6 & 0.1\end{array}$


Given the posterior belief, plugging the parameter values in Numerical Example 3 into Condition 3, reduces the value to $1.1525>1.0025$. In this example, because $x_{h}^{\prime}$ is a moderate policy change and the political cost of rejecting it outweighs the dissatisfaction of the rich, the policymaker accepts $x_{h}^{\prime}$. Given the posterior belief, plugging the parameter values in Numerical Example 3 into Rejection Condition 4, reduces the value to $1.1<1.24$. In this example, $H$ is politically dominant and $x_{l}^{\prime}$ is too drastic a policy change; therefore, the policymaker rejects $x_{l}^{\prime}$. In this case, the associated Acceptance Condition 3 and the associated Rejection Condition 4 are satisfied. From this example, $\{\alpha=1, \beta=1\}$ and $\{$ accept, reject $\}$ and $\left\{x_{h}^{\prime}, x_{h}\right\}$ constitute a pooling equilibrium outcome.

Result 5: $\{\alpha=1, \beta=1\}$ with a moderate policy change

1. There exists a pooling equilibrium, the policy change towards $x_{h}^{\prime}$ (i.e. a moderate policy change), despite the weak political power of the middle class.

2. Internal allegiance: the policy transition towards $x_{h}^{\prime}$ is unconditionally supported by the lower middle class.

3. External allegiance: the policy transition towards $x_{h}^{\prime}$ is unconditionally supported by the poor.

Case 2: $\alpha=\mathbf{0}$ and $\beta=\mathbf{0}$

As with the case in which the status quo is $x_{l}$, we need to check whether it is incentive compatible for the upper middle class to send the message, $x_{l}^{\prime}$, which implies a drastic 
policy change. If $\left|x_{h}^{\prime}-x_{l}^{\prime}\right|>\left|x_{h}^{\prime}-x_{h}\right|$, the upper middle class never sends the same message as the lower middle class.

Result 6: $\{\alpha=1, \beta=1\}$ with a drastic policy change

1. There exists a pooling equilibrium, the policy change towards $x_{l}^{\prime}$ (i.e. an extreme policy change) by accompanied by the restriction of $\left|x_{h}^{\prime}-x_{l}^{\prime}\right|<\left|x_{h}^{\prime}-x_{h}\right|$.

2. External allegiance: the policy transition towards $x_{l}^{\prime}$ is unconditionally supported by the poor.

(2) Separating equilibrium: $\alpha=1$ and $\beta=0$

\section{Case 1: $\{\alpha=1, \beta=0\}$ and \{accept, accept $\}$}

When a separating strategy $\{\alpha=1, \beta=0\}$ is chosen by the middle class, the associated Acceptance Ccondition 3 for $x_{h}^{\prime}$ is $M p\left(x_{h}-x_{h}^{\prime}\right)^{2}+L\left(x_{h}-x_{l}\right)^{2}>$ $L\left(x_{h}^{\prime}-x_{l}\right)^{2}+H\left(x_{h}^{\prime}-x_{h}\right)^{2}$ and the associated Acceptance Ccondition 4 for $x_{l}^{\prime}$ is $M(1-$ $p)\left(x_{h}-x_{h}^{\prime}\right)^{2}+L\left(x_{h}-x_{l}\right)^{2}>L\left(x_{l}^{\prime}-x_{l}\right)^{2}+H\left(x_{l}^{\prime}-x_{h}\right)^{2}$. In spite of the weak political power of the middle class, its ideal policy $\left\{x_{h}^{\prime}, x_{l}^{\prime}\right\}$ is adopted in both states. However, to induce a separating equilibrium, we need a stronger restriction on the political power distribution between the social groups, as the following example indicates.

Numerical Example $4\{\alpha=1, \beta=0\}$ and \{accept, accept $\}$

$\begin{array}{ccccccccc}H & M & L & x_{l}-x_{h} & x_{l}-x_{h}^{\prime} & x_{h}^{\prime}-x_{h} & x_{l}-x_{l}^{\prime} & x_{l}^{\prime}-x_{h} & x_{l}^{\prime}-x_{h}^{\prime} \\ 3 & 0.7 & 2 & 1 & 0.7 & 0.3 & 0.4 & 0.6 & 0.3\end{array}$


By plugging the parameter values in Numerical Example 4 into Condition 3 and Condition 4, the values are reduced to $1.555>2.0315$ and $2.0315>1.4$ respectively. Since $\left(x_{h}^{\prime}-x_{h}\right)$ is small, the degree of opposition of the rich is mitigated. Then, the policymaker accepts $x_{h}^{\prime}$. The combined the opposition of the poor and the upper middle class against the current status quo compels the policymaker to accept $x_{l}^{\prime}$. As $p$ increases, Acceptance Condition 3 is easily satisfied; however, Acceptance Condition 4 is harder to satisfy. As $p$ grows, the political cost of rejecting $x_{l}^{\prime}$ becomes smaller, leading to the following types of separating equilibrium.

Case 2: $\{\alpha=1, \beta=0\}$ and $\{$ accept, reject $\}$

In a separating equilibrium, with a high value of $p$, the ideal policy for the lower middle class is rejected, and only the ideal policy for the upper middle class is accepted. The higher proportion of the upper middle class may prohibit the realization of the ideal policy for the lower middle class. The welfare level of the upper middle class improves. While the poor are better off, the rich are the losers.

Result 7: a separating equilibrium of $\{\alpha=1, \beta=0\}$ and \{accept, reject $\}$

1. As the proportion of the upper middle $(p)$ increases, the probability that the ideal policy of the remaining subgroup $(1-p)$ is rejected increases.

2. Regardless of the current status quo (i.e. $x_{l}^{\prime}$ or $x_{h}^{\prime}$ ), in a type of separating equilibrium of $\{\alpha=1, \beta=0\}$ and $\{$ accept, reject $\}$, there exists a conflict of interest between subgroups within the middle class. 
3. As $p$ and $\left|x_{h}^{\prime}-x_{l}^{\prime}\right|$ increase, the welfare of a minor subgroup (i.e., lower middle class) worsens.

\section{Conclusion}

The "Director's Law" is consistent with the standard median voter theorem. However, our paper asserts that the middle class overrepresentation in the welfare state is deeply related to the implicit allegiance with other social groups. We also assume that the middle class consists of two subgroups, and upper middle class and a lower middle class. The internal allegiances within the middle class have not been addressed before. When the upper middle class and the lower middle class articulate the same political messages to the policymaker, the middle class obtains its ideal policy if it pursues a moderate policy change from the current status quo.

This allegiance, within the middle class, is captured by the pooling equilibrium of the model. We showed that there exists a pooling equilibrium which supports policy change toward the ideal policy of the middle class. This pooling equilibrium is robust in the sense that even if the differences between political powers are significant, an equilibrium which benefits the middle class exists. In the case of an important policy change, a conflict of interest between the upper and lower middle class may arise. This conflict is avoided if the ideal policies of the two subgroups are very close.

A separating equilibrium where the ideal policies of the upper middle class are adopted exists if the differences in political power between social groups are small. It is interesting to note that in a separating equilibrium as the proportion of the upper middle class increases, the probability of rejecting the proposal of the lower middle increases. If 
the policy change is substantial, a separating equilibrium is not robust, it may increase the divergence within the middle class, and weaken the political power of the middle class. Policy transition toward $x_{h}^{\prime}$ or $x_{l}^{\prime}$ is unconditionally supported by the rich or the poor. According to our model, the middle class achieves its ideal policy through the internal allegiance and outside support from the poor or the rich. But, the degree of policy change should be moderate, because drastic policy changes may generate a conflict of interests within the middle class. 


\section{$\underline{\text { Appendix }}$}

\section{Ex-post payoffs of middle class when status quo is $x_{l}$}

- $\left(x_{h}^{\prime}-x_{h}^{\prime}\right)^{2}$, where proposed policy $x_{h}^{\prime}$ is adopted in $S=G$ and status quo is $x_{l}$

- $\left(x_{l}-x_{h}^{\prime}\right)^{2}$, where proposed policy $x_{h}^{\prime}$ is rejected in $S=G$ and status quo is $x_{l}$

- $\left(x_{l}^{\prime}-x_{h}^{\prime}\right)^{2}$, where proposed policy $x_{l}^{\prime}$ is adopted in $S=G$ and status quo is $x_{l}$

- $\left(x_{l}-x_{h}^{\prime}\right)^{2}$, where proposed policy $x_{l}^{\prime}$ is rejected in $S=G$ and status quo is $x_{l}$

- $\left(x_{h}^{\prime}-x_{l}^{\prime}\right)^{2}$, where proposed policy $x_{h}^{\prime}$ is adopted in $S=B$ and status quo is $x_{l}$

- $\left(x_{l}-x_{l}^{\prime}\right)^{2}$, where proposed policy $x_{h}^{\prime}$ is rejected in $S=B$ and status quo is $x_{l}$

- $\left(x_{l}^{\prime}-x_{l}^{\prime}\right)^{2}$, where proposed policy $x_{l}^{\prime}$ is adopted in $S=B$ and status quo is $x_{l}$

- $\left(x_{l}-x_{l}^{\prime}\right)^{2}$, where proposed policy $x_{l}^{\prime}$ is rejected in $S=B$ and status quo is $x_{l}$

\section{Ex-post payoffs of politician when status quo is $x_{l}$}

- $M\left(x_{h}^{\prime}-x_{h}^{\prime}\right)^{2}-L\left(x_{h}^{\prime}-x_{l}\right)^{2}-H\left(x_{h}^{\prime}-x_{h}\right)^{2}$, where proposed policy $x_{h}^{\prime}$ is adopted

- $M\left(x_{l}-x_{h}^{\prime}\right)^{2}-L\left(x_{l}-x_{l}\right)^{2}-H\left(x_{l}-x_{h}\right)^{2}$, where proposed policy $x_{h}^{\prime}$ is rejected

- $M\left(x_{l}^{\prime}-x_{h}^{\prime}\right)^{2}-L\left(x_{l}^{\prime}-x_{l}\right)^{2}-H\left(x_{l}^{\prime}-x_{h}\right)^{2}$, where proposed policy $x_{l}^{\prime}$ is adopted

- $M\left(x_{l}-x_{h}^{\prime}\right)^{2}-L\left(x_{l}-x_{l}\right)^{2}-H\left(x_{l}-x_{h}\right)^{2}$, where proposed policy $x_{l}^{\prime}$ is rejected

- $M\left(x_{h}^{\prime}-x_{l}^{\prime}\right)^{2}-L\left(x_{h}^{\prime}-x_{l}\right)^{2}-H\left(x_{h}^{\prime}-x_{h}\right)^{2}$, where proposed policy $x_{h}^{\prime}$ is adopted

- $M\left(x_{l}-x_{l}^{\prime}\right)^{2}-L\left(x_{l}-x_{l}\right)^{2}-H\left(x_{l}-x_{h}\right)^{2}$, where proposed policy $x_{h}^{\prime}$ is rejected

- $M\left(x_{l}^{\prime}-x_{l}^{\prime}\right)^{2}-L\left(x_{l}^{\prime}-x_{l}\right)^{2}-H\left(x_{l}^{\prime}-x_{h}\right)^{2}$, where proposed policy $x_{l}^{\prime}$ is adopted

- $M\left(x_{l}-x_{l}^{\prime}\right)^{2}-L\left(x_{l}-x_{l}\right)^{2}-H\left(x_{l}-x_{h}\right)^{2}$, where proposed policy $x_{l}^{\prime}$ is rejected 


\section{Ex-post payoffs of politician when status quo is $x_{h}$}

- $M\left(x_{h}^{\prime}-x_{h}^{\prime}\right)^{2}-L\left(x_{h}^{\prime}-x_{l}\right)^{2}-H\left(x_{h}^{\prime}-x_{h}\right)^{2}$, where proposed policy $x_{h}^{\prime}$ is adopted

- $M\left(x_{h}-x_{h}^{\prime}\right)^{2}-L\left(x_{h}-x_{l}\right)^{2}-H\left(x_{h}-x_{h}\right)^{2}$, where proposed policy $x_{h}^{\prime}$ is rejected

- $M\left(x_{l}^{\prime}-x_{h}^{\prime}\right)^{2}-L\left(x_{l}^{\prime}-x_{l}\right)^{2}-H\left(x_{l}^{\prime}-x_{h}\right)^{2}$, where proposed policy $x_{l}^{\prime}$ is adopted

- $M\left(x_{h}-x_{h}^{\prime}\right)^{2}-L\left(x_{h}-x_{l}\right)^{2}-H\left(x_{h}-x_{h}\right)^{2}$, where proposed policy $x_{l}^{\prime}$ is rejected

- $M\left(x_{h}^{\prime}-x_{l}^{\prime}\right)^{2}-L\left(x_{h}^{\prime}-x_{l}\right)^{2}-H\left(x_{h}^{\prime}-x_{h}\right)^{2}$, where proposed policy $x_{h}^{\prime}$ is adopted

- $M\left(x_{h}-x_{l}^{\prime}\right)^{2}-L\left(x_{h}-x_{l}\right)^{2}-H\left(x_{h}-x_{h}\right)^{2}$, where proposed policy $x_{h}^{\prime}$ is rejected

- $M\left(x_{l}^{\prime}-x_{l}^{\prime}\right)^{2}-L\left(x_{l}^{\prime}-x_{l}\right)^{2}-H\left(x_{l}^{\prime}-x_{h}\right)^{2}$, where proposed policy $x_{l}^{\prime}$ is adopted

- $M\left(x_{h}-x_{l}^{\prime}\right)^{2}-L\left(x_{h}-x_{l}\right)^{2}-H\left(x_{h}-x_{h}\right)^{2}$, where proposed policy $x_{l}^{\prime}$ is rejected 


\section{Chapter 4}

Apportionment Formula and Strategic Competition 


\section{Introduction}

If a corporation has business activities located in multiple jurisdictions, then the local authority can levy a tax on income generated in that state. However, as measuring income earned within each jurisdiction presents a difficult conceptual problem, a system of formula apportionment to allocate income across states is usually adopted. Formula apportionment, as used in the U.S., asserts that the proportion of a multi-state firm's income earned in a given state is a weighted average of the proportion of the firm's total sales, property, and payroll in that state. Specifically, the tax due by a multi-state firm to state $\mathrm{i}$ is

$$
T_{i}=t_{i}\left[m_{K}^{i} \frac{K_{i}}{K}+m_{W}^{i} \frac{W_{i}}{W}+m_{S}^{i} \frac{S_{i}}{S}\right] \pi_{i}^{T},
$$

where $K_{i}, W_{i}$ and $S_{i}$ are property, payroll, and sales in state i, respectively; K, W, and S are total domestic property, payroll, and sales of the firm respectively; $m_{j}^{i}$ is the weight given to factor $\mathrm{j}$ in the apportionment formula in state $\mathrm{i} ; \pi_{i}^{T}$ represents total profits of the multi-state firm as defined by state i's tax law; and $t_{i}$ is state i's tax rate.

Table 1 shows the weights $m_{j}^{i}$ chosen by different states in the US. In general, states do not follow a single principle. If they all adopt the same apportionment formula, exactly 100 percent of a corporation’s income will be apportioned across states. Non-uniformity, however, can result in more or less than 100 percent of a corporation's income being subject to state income tax.

In an effort to encourage tax uniformity, the Multi-state Tax Compact in 1967 established that the three factors considered in the apportionment formula are to be weighted equally. In spite of the compact, most states have recently deviated from the 
uniform formula apportionment and moved towards a greater weight on the sales portion of the corporate income tax, as it is clear from Table 1. It has been claimed that by manipulating the formula in this way, officials can offer tax breaks that help the economic development of the region. If more states pass such legislation, other states will be compelled to do the same, initiating a "race to the bottom", in which all states end up imposing the same (lower) tax liability.

The choice of the specific formula apportionment is an avenue through which tax competition between state governments occurs. The apportionment of a firm's total profits across states creates complicated incentive effects. On one hand, firms operating in different regions will react to different formula by changing the allocation of property, of sales and of workers across regions. On the other hand, given that the tax policy selected by different state governments affects residents of other states, some kind of strategic interaction can be expected. ${ }^{7}$

Separating accounting is an alternative for formula apportionment. According to Pethig and Wagner (2003), "In the European Union, it is worried that the investment across the member countries is heavily taxed due to the member country's uncoordinated tax scheme. Current separating accounting system requires the firm to set up the profit center for each member countries, incurring high monitoring cost of tax authority and high compliance cost of the firm who have to deal with. This induces firm's investment shift from high tax region to low tax region.” Under separating accounting system, there is no way for individual tax authorities to have comprehensive information about the

\footnotetext{
${ }^{7}$ Wall Street Journal, February 14 2001, reports, "Proponents say the single sales factor is good for the economic growth because it eliminates the disincentive to corporate investment inherent in the traditional formula. But there is a dark side to these gains. Everyone is racing to get there first, but once everybody gets there, the benefits go away.”
} 
overall activities of the firm, as the real profit of each subsidiary in each nation is distorted by the transfer pricing policy of the multinational firm across the border. Since the cost of the transfer pricing between subsidiaries and the headquarter of the multinational firm cannot be exactly observed, the multinational firm has strong incentives to manipulate the transfer pricing which affects the tax base. Anticipating this strategic behavior of the firm, the tax authorities spend higher cost for monitoring. Compliance cost of the firm might be huge. Since the multinational firm in EU should deal with different tax schemes for its member countries, the firms are reluctant to invest in different member countries and concentrate their investment in the lower tax rate zone. Separating accounting may induce this kind of tax competition which is contrary to the objective of EU. As the EU economy becomes integrated, in order to deal with tax coordination and tax competition, the experience of the US in formula apportionment invokes interest in EU countries.

The literature about formula apportionment is closely related to the corresponding literature that examines the relationship between national tax systems and the strategic decisions on the part of multinational enterprises concerning the location of their investment, production and profits in particular, the allocation of foreign direct investment across countries.

The present paper extends the formula apportionment literature by considering the effect of different formulas on the equilibrium tax rate and the provision of local goods. The model assumes that the strategic determination of the corporate tax rates by local authorities affects the localization of a multi-jurisdictional firm's activities. Given the complicated incentive effects generated by this tax system, the model analyzes the 
outcome of a symmetric equilibrium. The paper concludes that due to the strategic interaction between local governments, the equilibrium tax rate is inefficiently low, which might cause underprovision of the public good. In addition, the inefficiency is more severe in a formula apportionment that employs capital shares as a measure of the firms' activities in each state, compared to output (or sales) shares. As a result, the shift towards a (symmetric) formula apportionment under output (sales) shares constitutes an improvement for the economy. ${ }^{8}$

Even though there seems to be a great interest in the US and the EU in the strategic modification of apportionment formulas among state governments (Nielsen et al. 2000), only recently has this issue been formally examined. The earlier papers by McClure (1980) and McClure (1981) first elucidated that formula apportionment mostly transforms the state corporate income tax into three separate taxes on the factors in the apportionment formula. Anand and Sansing (2000) provide an explanation for why states choose different apportionment formula, even though aggregate social welfare is maximized when states use the same formula. They demonstrate analytically that “importing” states have incentives to increase sales factor weights, while "exporting” states have incentives to reduce the weights on productive factors. Our analysis shows that capital outflow is less sensitive under output shares formula apportionment than capital shares formula apportionment.

Gordon and Wilson (1986) examine the response of firms to a system of formula apportionment, restricting attention to cases in which all states use the same system, with different corporate tax rates. Their paper shows that the public good is underprovided and

\footnotetext{
8 “State corporate income taxes raised $\$ 32$ billion in 2001, accounting for just 5.7 percent of state tax revenues and 2.7 percent of total state revenues. These shares have declined since the late 1970s” (Edwards, 2004)
} 
the utility level is lower under a formula apportionment system compared to property taxation. We obtain a similar result, but the main difference is that we also find that the inefficiency is more severe under a formula apportionment that exclusively considers capital shares relative to one that only employs sales shares, leading to a lower level of welfare in the regions. As a result, a transition towards a formula apportionment that gives more importance to the sales proportion (which is consistent with the evidence from US) might constitute a welfare improvement for the economy as a whole.

Goolsbee et al (2000) provides empirical support to the fact that a change of the formula apportionment creates negative externalities on other states, “creating pressure for states to act first in changing their formulae”. Edmiston (2002) finds that single-factor sales policies have positive effects on the economic development. Our paper explicitly considers the negative externalities created by the strategic determination of the corporate tax rates and shows that MRS between the private good and the publicly provided local good under formula apportionment at federal government level is lower than MRS under formula apportionment at local government level.

\section{Model}

\section{1. Outline of the game between the local government and the multi state firm}

There are two regions: region 1 and region 2. Each one is inhabited by a representative consumer and a local government. A multi-state firm operates in both regions at the same time. The technology is described by an increasing and strictly concave production function $f(k)$, where capital is the only input. Capital can be rented in a perfectly competitive capital market at price $r$. Figure 8 describes the sequence of events in our model. 
Figure 8: FA policy and reaction of multistate firm

\begin{tabular}{|c|c|c|}
\hline 0 & 1 & 2 \\
\hline $\begin{array}{c}\text { Local governments announce FA } \\
\text { and corporate income tax rates }\end{array}$ & $\begin{array}{c}\text { Firm observes the tax policy and } \\
\text { allocates capital across regions }\end{array}$ & Payoffs are realized \\
\hline
\end{tabular}

In the first stage, the local government announces its corporate income tax rate and the formula apportionment. The tax revenue is entirely used to finance the publicly provided local good. At the second stage of the game, after observing the tax rate and apportionment formula, the multi-state firm chooses its optimal level of capital in each region. The decisions made by the firm at the second stage of the game are rationally anticipated by the local government. The sub-game perfect equilibrium depends on the apportionment formula and tax rates chosen by the local governments, and the allocation of capital across regions. In order to derive the equilibrium conditions, we first need to investigate the firm's reaction to different tax rates. Due to the complexity of the analysis, we focus in a symmetric equilibrium.

\subsection{Firm's profit maximization}

The production function $f\left(k_{i}\right), i=1,2$, is strictly concave and identical in both regions, $r$ is the cost of capital, and $t_{1}$ and $t_{2}$ are the corporate income tax rates levied in each region. Following Pethig et al (2003), we denote $\alpha\left(k_{1}, k_{2}\right)$ the firm's activities in region 1 , and $\beta\left(k_{1}, k_{2}\right)$ the firm's activities in region 2 . The effective tax rate faced by the firm is given by $t=t_{1} \alpha\left(k_{1}, k_{2}\right)+t_{2} \beta\left(k_{1}, k_{2}\right)$. Corporate income tax deduction is applied to the cost of capital financed from capital markets with the degree of $\mu$ (see, for instance Wilson (1986)). We assume that both local governments adopt the same deduction policy $\mu$. Most existing tax systems permit only incomplete deduction of capital costs. This 
corresponds to $\mu<1$, which means that a positive tax is also levied on capital. For $\mu=1$, the corporate tax falls only on pure profits, and when $\mu>1$ capital is subsidized. The multi-state firm solves the following problem. It maximizes profits by choosing $k_{1}$ and $k_{2}$, given the tax rate, the formula apportionment, and the deduction policy imposed by the local governments:

$\max _{k_{1}, k_{2}} \mathrm{~V}\left(k_{1}, k_{2} ; t_{1}, t_{2}, \mu\right)=[(1-t) \pi-t(1-\mu) k r]$, where $\pi=\left[f\left(k_{1}\right)-r k_{1}+f\left(k_{2}\right)-r k_{2}\right]$.

From the FOCs, the following expressions are obtained in a symmetric equilibrium (i.e. $t_{1}$ $\left.=t_{2}\right)$

$$
\left[f^{\prime}\left(k_{1}\right)-r\right]=\frac{t}{1-t}(1-\mu) r \text { and }\left[f^{\prime}\left(k_{2}\right)-r\right]=\frac{t}{1-t}(1-\mu) r \text {. }
$$

Due to the presence of the deduction policy $\mu$, even in the symmetric equilibrium there is still a distortion in the capital allocation across regions. We can now derive the reaction of the multi-state firm to a change in the tax rate (again evaluated at a symmetric equilibrium):

$$
\begin{aligned}
\frac{\partial k_{1}}{\partial t_{1}}= & \frac{1}{(1-t) f^{\prime \prime}\left(k_{1}\right)}\left\{\frac{\alpha(1-\mu) r}{(1-t)}+\alpha_{1}[\pi+(1-\mu) k r]\right\}, \\
\frac{\partial k_{2}}{\partial t_{1}}= & \frac{1}{(1-t) f^{\prime \prime}\left(k_{2}\right)}\left\{\frac{\alpha(1-\mu) r}{(1-t)}-\beta_{2}[\pi+(1-\mu) k r]\right\}, \\
& \text { where } \alpha_{1}=\frac{\partial \alpha\left(k_{1}, k_{2}\right)}{\partial k_{1}} \text { and } \beta_{2}=\frac{\partial \beta\left(k_{1}, k_{2}\right)}{\partial k_{2}} .
\end{aligned}
$$

Result 1: When the local government employs exclusively a formula that only weighs capital (i.e. $m_{1}{ }^{k}=1$ ), the following results hold:

$$
\frac{\partial k_{1}}{\partial t_{1}}=\frac{1}{(1-t) f^{\prime \prime}\left(k_{1}\right)} \frac{1}{2}\left\{\frac{(2-t)(1-\mu) r}{(1-t)}+\frac{\pi}{k}\right\}<0
$$




$$
\frac{\partial k_{2}}{\partial t_{1}}=\frac{1}{(1-t) f^{\prime \prime}\left(k_{2}\right)} \frac{1}{2}\left\{\frac{(t)(1-\mu) r}{(1-t)}-\frac{\pi}{k}\right\} .
$$

Moreover,

$$
\begin{aligned}
& \frac{\partial k_{2}}{\partial t_{1}}>0 \text { if } \frac{t(1-\mu) r k}{(1-t)}<\pi, \\
& \frac{\partial k_{2}}{\partial t_{1}}=0 \text { if } \frac{t(1-\mu) r k}{(1-t)}=\pi, \\
& \frac{\partial k_{2}}{\partial t_{1}}<0 \text { if } \frac{t(1-\mu) r k}{(1-t)}>\pi
\end{aligned}
$$

An increase in the tax rate under a full capital share formula apportionment induces capital to leave the region. However, it is uncertain whether an increase in the tax rate of region 1 benefits the neighboring region. A positive externality to region 2 is observed only if $\frac{t(1-\mu) r k}{(1-t)}<\pi$. When $\mu=1, \frac{\partial k_{2}}{\partial t_{1}}$ is always positive ${ }^{9}$, and if $\mu<1$, the sign of $\frac{\partial k_{2}}{\partial t_{1}}$ is not monotonic, while the sign of $\frac{\partial k_{1}}{\partial t_{1}}$ is always negative. For example, consider the case $\frac{t(1-\mu) r k}{(1-t)}>\pi$, where $\frac{\partial k_{2}}{\partial t_{1}}<0$. In this case of negative net profits, the increase of tax rate in region 1 decreases capital investment in region 2 as well as in region 1 . In the case of zero profits, the increase of tax rate in region 1 does not create a positive externality in capital investment in region 2. Disregarding those exceptional cases of negative net profits and zero profits, we can claim that the capital outflow toward a neighboring region is caused by the increase in the tax rate of the region, creating an

${ }^{9}$ Without deduction policy, $\frac{\partial k_{1}}{\partial t_{1}}=\frac{\alpha_{1} \pi}{(1-t) f^{\prime \prime}\left(k_{1}\right)}<0, \frac{\partial k_{2}}{\partial t_{1}}=\frac{\alpha_{2} \pi}{(1-t) f^{\prime \prime}\left(k_{2}\right)}>0$. 
externality between state governments. The comparative static results $\frac{\partial k_{1}}{\partial t_{1}}<0$ and $\frac{\partial k_{2}}{\partial t_{1}}>$ 0 become the foundation of the tax competition between state governments.

Result 2: When the local government employs exclusively a formula that only weighs sales (i.e. $m_{1}^{S}=1$ ), the following results hold:

$$
\begin{aligned}
& \frac{\partial k_{1}}{\partial t_{1}}=\frac{1}{(1-t) f^{\prime \prime}\left(k_{1}\right)} \frac{1}{2}\left\{\frac{(1-\mu) r}{(1-t)}+\frac{f^{\prime}\left(k_{1}\right)}{2 f\left(k_{1}\right)}[\pi+(1-\mu) k r]\right\}<0 \\
& \frac{\partial k_{2}}{\partial t_{1}}=\frac{1}{(1-t) f^{\prime \prime}\left(k_{2}\right)} \frac{1}{2}\left\{\frac{(1-\mu) r}{(1-t)}-\frac{f^{\prime}\left(k_{2}\right)}{2 f\left(k_{2}\right)}[\pi+(1-\mu) k r]\right\} .
\end{aligned}
$$

Moreover,

$$
\begin{aligned}
& \frac{\partial k_{2}}{\partial t_{1}}>0 \text { if } \frac{(1-\mu) r}{(1-t)}<\frac{f^{\prime}\left(k_{2}\right)}{2 f\left(k_{2}\right)}[\pi+(1-\mu) k r], \\
& \frac{\partial k_{2}}{\partial t_{1}}=0 \text { if } \frac{(1-\mu) r}{(1-t)}=\frac{f^{\prime}\left(k_{2}\right)}{2 f\left(k_{2}\right)}[\pi+(1-\mu) k r], \\
& \frac{\partial k_{2}}{\partial t_{1}}<0 \text { if } \frac{(1-\mu) r}{(1-t)}>\frac{f^{\prime}\left(k_{2}\right)}{2 f\left(k_{2}\right)}[\pi+(1-\mu) k r] .
\end{aligned}
$$

An increase in the tax rate under a formula apportionment that exclusively considers the proportion of sales in the region induces capital to leave the region, as with a formula that only weighs capital shares. It is also uncertain whether an increase in the tax rate of region 1 benefits the neighboring region. The derivations of the previous results are in the Appendix. 


\subsection{State government problem with formula apportionment}

The representative resident's welfare is determined by the level of the publicly provided local good and private consumption good. We assume that the welfare function is identical across regions. Corporate income taxes are used to finance the state government's expenditure. We assume that a balanced budget constraint is maintained. The private good consumption is given by an exogenously predetermined share $(\theta)$ of the net total profit of the multi-state firm. Then, the state government of region 1 solves the following problem:

$\max _{t_{1}} \mathrm{U}\left(g_{1}, x_{1}\right)$,

where $g_{1}=t_{1} \frac{k_{1}}{k}[\pi+(1-\mu) k r]=t_{1} \alpha\left(k_{1}, k_{2}\right)[\pi+(1-\mu) k r], x_{1}=\theta[(1-t) \pi$

- $t(1-\mu) k r]$, and $\pi=\left[f\left(k_{1}\right)-r k_{1}+f\left(k_{2}\right)-r k_{2}\right]$.

At a symmetric equilibrium,

$$
\begin{aligned}
& \frac{\partial x_{1}}{\partial t_{1}}=-\theta \alpha\left(k_{1}, k_{2}\right)[\pi+(1-\mu) k r] \\
& \frac{\partial g_{1}}{\partial t_{1}}=\alpha\left(k_{1}, k_{2}\right)[\pi+(1-\mu) k r]+t(1-t) f^{\prime \prime}\left(k_{1}\right)\left[\left(\frac{\partial k_{1}}{\partial t_{1}}\right)^{2}+\left(\frac{\partial k_{2}}{\partial t_{1}}\right)^{2}\right],
\end{aligned}
$$

and the level of $g_{1}$ is determined by:

$$
\operatorname{MRS}^{F A}=\theta \gamma \text {, where } \gamma=\frac{\frac{1}{2}[\pi+(1-\mu) k r]}{\frac{1}{2}[\pi+(1-\mu) k r]+t(1-t) f^{\prime \prime}\left(k_{1}\right)\left[\left(\frac{\partial k_{1}}{\partial t_{1}}\right)^{2}+\left(\frac{\partial k_{2}}{\partial t_{1}}\right)^{2}\right]}
$$

The MRS includes both the reaction of the firm to the tax policy (which is the main source of tax competition between local governments), and the shape of production 
technology. It is straightforward to show that efficiency requires that MRS $=1 .^{10}$

Therefore, MRS > 1 implies that the tax rate is inefficiently low compared to the efficient level.

$\underline{\text { Result 3: }}$ Let MRS $=\theta \gamma$, where $\gamma=\frac{\frac{1}{2}[\pi+(1-\mu) k r]}{\frac{1}{2}[\pi+(1-\mu) k r]+t(1-t) f^{\prime \prime}\left(k_{1}\right)\left[\left(\frac{\partial k_{1}}{\partial t_{1}}\right)^{2}+\left(\frac{\partial k_{2}}{\partial t_{1}}\right)^{2}\right]}$.

If $\gamma>2$ and $\theta=0.5$, then MRS $>1$ taxes are inefficiently low at a symmetric equilibrium.

This welfare loss condition holds for both types of formula apportionment considered in this paper, i.e. a formula apportionment that only weighs capital shares and a formula apportionment that only considers sales shares. Let $\theta=0.5$ and $\gamma$ is larger than 2 . Given $\theta=0.5, \gamma>2$ implies that reactions of the multistate firm to the change in tax rate are sensitive at the capital investment level within a specific type of formula apportionment. Reactions of the multistate firm are key determinants of $\gamma$. As result 1 and result 2 indicates, the multistate firm's reaction at the symmetric equilibrium are different by a formula apportionment policy.

Therefore, we can conclude that different formula apportionment policies (i.e. capital shares vs sales shares) adopted by state governments in U.S. induce different

10 Let $t_{1}, t_{2}$ solve the following problem: max $\mathrm{U}\left(g_{1}, x_{1}\right)+\mathrm{U}\left(g_{2}, x_{2}\right)$, where $x_{1}+x_{2}+g_{1}+g_{2}=$ $\left[f\left(k_{1}\right)-r k_{1}+f\left(k_{2}\right)-r k_{2}\right]$. In this case MRS $=-\frac{U_{g_{1}}}{U_{x_{1}}}=\frac{\partial x_{1}}{\partial g_{1}}$ at symmetric equilibrium. Since $\frac{\partial x_{1}}{\partial t_{1}}=\left[f^{\prime}\left(k_{1}\right)-\right.$ r] $\frac{\partial k_{1}}{\partial t_{1}}$ and $\frac{\partial g_{1}}{\partial t_{1}}=\left[f^{\prime}\left(k_{1}\right)-r\right]$, we obtain MRS $=1$. At the efficient level of tax rate, MRS $=1$, so that if MRS $>1$, $t_{1}$, and $t_{2}$ would be inefficiently low. 
welfare impacts on the regions including their neighboring regions. As far as $\gamma>2$, regardless of formula apportionment policies, the states experience welfare loss. Since the absolute value of $\frac{\partial k_{1}}{\partial t_{1}}$ and $\frac{\partial k_{2}}{\partial t_{1}}$ can be interpreted as the degree of tax competition between the local governments, as these expressions become larger, or alternatively when capital becomes responsive to changes in the tax rates, the regions experience larger welfare losses (in other words, the MRS in equilibrium will increase). Because $\frac{\partial k_{1}}{\partial t_{1}}$ and $\frac{\partial k_{2}}{\partial t_{1}}$ are different according to formula apportionment policies, the welfare level of regions is relied on two factors; the degree of tax competition and formula apportionment policies including tax policy adopted by neighboring regions.

In the first part of next section, we analyze the welfare impact relying on the different formula apportionment policies. Tax competition and formula apportionment policy in a region generate externalities to neighboring regions. If a federal government implements formula apportionment rule, then externalities can be internalized. In the second part of next section, we compare the welfare impact of FA managed by a state government with the welfare impact of FA managed by a federal government.

\section{Analysis}

\section{1. Comparison output shares and capital shares formula apportionment.}

Our objective is to compare the welfare effect of an equally weighted three-factor formula with a formula that exclusively considers capital or sales shares. A three-factor equally weighted formula apportionment is a convex combination of a formula that only 
considers the sales, the capital and the wage factor. Since the firm produces its output by using capital and labor, the capital and the wage factor in the formula apportionment can be grouped in a single category. To compare the welfare impact, we calculate MRS ${ }^{F A}$ under an output (sales) share formula apportionment and MRS ${ }^{F A}$ under a capital share formula apportionment respectively. ${ }^{11}$

The MRS is affected by the absolute values of $\frac{\partial k_{1}}{\partial t_{1}}$ and $\frac{\partial k_{2}}{\partial t_{1}}$. These expressions are different under different formula apportionment systems. Let $\left.\frac{\partial k_{1}}{\partial t_{1}}\right|^{k}$ be the reaction under capital share and $\left.\frac{\partial k_{1}}{\partial t_{1}}\right|^{f}$ be the reaction under output share. Due to decreasing returns to scales, it is easy to show that that $\left.\frac{\partial k_{1}}{\partial t_{1}}\right|^{k}$ and $\left.\frac{\partial k_{2}}{\partial t_{1}}\right|^{k}$ are larger than $\left.\frac{\partial k_{1}}{\partial t_{1}}\right|^{f}$ and $\left.\frac{\partial k_{2}}{\partial t_{1}}\right|^{f}$ in absolute value, respectively. The proof is provided in the Appendix. In addition, note that if $\operatorname{MRS}_{F A}^{f}>1$, then $\operatorname{MRS}_{F A}^{k}>1$, i.e., $\operatorname{MRS}_{F A}^{k}>\operatorname{MRS}_{F A}^{f}>1$. This result states that if tax rates are inefficiently low when regions employ a formula apportionment based exclusively on sales shares, then the distortion will be more important under a formula apportionment that only weighs capital shares. Under output shares, a change in the tax rate affects investment decisions through the production technology. But, the production function is strictly concave, this concavity smoothes the impact of the change in the tax rate. Under capital shares, the change in the tax rate directly affects the allocation of capital. Hence, the local government will experience a serious capital outflow to the neighboring region. This result can be summarized as follows.

${ }^{11}$ At a symmetric equilibrium, output and sales are identical. 
Result 4: $\operatorname{MRS}_{F A}^{k}=\theta \gamma^{k}>\operatorname{MRS}_{F A}^{f}=\theta \gamma^{f}$, where $\gamma^{k}$ is based on $\left.\frac{\partial k_{1}}{\partial t_{1}}\right|^{k}$ and $\left.\frac{\partial k_{2}}{\partial t_{1}}\right|^{k}$, while $\gamma^{f}$ is based on $\left.\frac{\partial k_{1}}{\partial t_{1}}\right|^{f}$ and $\left.\frac{\partial k_{2}}{\partial t_{1}}\right|^{f}$. Then, if $\operatorname{MRS}_{F A}^{f}=\theta \gamma^{f}>1$, a formula apportionment that only weighs sales shares provides a higher welfare level relative to one that exclusively weighs capital shares.

As a result, the shift toward a formula apportionment under output shares constitutes an improvement for the economy as a whole. This is because capital becomes less responsive to changes in tax rates when output shares are used as opposed to capital shares. A lower response under output shares, implies that tax rates will not be as low as in the case of capital shares. A formula apportionment that gives equal weights to capital and output is a convex combination of the latter two cases. Then, the Multi-state Tax Compact in 1967 can be represented by MRS $\frac{1}{2 k+\frac{1}{2} f}$. As the value of $\operatorname{MRS}_{F A}^{\frac{1}{2} k+\frac{1}{2} f}$, in equilibrium, is a convex combination of $\mathrm{MRS}_{F A}^{k}$ and $\mathrm{MRS}_{F A}^{f}$, we have that:

$$
\operatorname{MRS}_{F A}^{k}>\operatorname{MRS}_{F A}^{\frac{1}{2} k+\frac{1}{2} f}>\operatorname{MRS}_{F A}^{f}
$$

This last relationship is consistent with a deviation from the Multi-state Tax Compact in 1967 towards a formula that exclusively weighs the sales portion.

The corporate income tax under a formula apportionment system can be decomposed into three separate taxes on the each factor (McClure, 1980). As the output share increases, the corporate income tax under formula apportionment approaches a pure sales tax. This is the reason why the absolute value of $\left.\frac{\partial k_{1}}{\partial t_{1}}\right|^{k}$ is bigger than the absolute 
value of $\left.\frac{\partial k_{1}}{\partial t_{1}}\right|^{f}$. By assigning a higher weight to the sales factor, the local government actually imposes a kind of sales tax on the firm rather than a property tax. As the sales factor is weighed more heavily, the effective tax rate imposed on capital becomes smaller. Hence, the capital outflow is smaller in this case relative to a formula that gives a higher weight to the capital factor.

\subsection{Comparison local formula apportionment and cooperative formula}

\section{apportionment}

In the previous section, we showed that under sales share, the tax rates are not as low as in the case of capital shares. In this section, we examine whether the cooperative formula apportionment between the local governments improves the welfare of the economy as a whole. ${ }^{12}$ Let us denote MRS under local government by $\mathrm{MRS}_{F A}^{\text {local }}$ and MRS under cooperative formula apportionment by $\mathrm{MRS}_{F A}^{\text {coop }}$. The cooperative optimal solution of the tax rate is given by solving the following problem:

$$
\begin{aligned}
& \max _{t_{1}, t_{2}} \mathrm{U}\left(g_{1}, x_{1}\right)+\mathrm{U}\left(g_{2}, x_{2}\right) \\
& \text { subject to } g_{1}=t_{1} \alpha\left(k_{1}, k_{2}\right)[\pi+(1-\mu) k r], g_{2}=t_{2} \beta\left(k_{1}, k_{2}\right)[\pi+(1-\mu) k r], \\
& x_{1}=\theta[(1-t) \pi-t(1-\mu) k r], \text { and } x_{2}=(1-\theta)[(1-t) \pi-t(1-\mu) k r], \text { where } \pi= \\
& {\left[f\left(k_{1}\right)-r k_{1}+f\left(k_{2}\right)-r k_{2}\right] .}
\end{aligned}
$$

The MRS between the publicly provided local good and the private good under capital share under the cooperative formula apportionment is described in the following result.

\footnotetext{
12 "Cooperative formula apportionment" is one in which local governments make an enforceable agreement on formula apportionment to be implemented and execute it without betrayal.
} 
Result 5: $\operatorname{MRS}_{F A}^{\text {coop }}=\theta \gamma^{\text {coop }}$, where $\gamma^{\text {coop }}$ is defined as

$$
\frac{\theta \frac{1}{2}[\pi+(1-\mu) k r]}{\frac{1}{2}[\pi+(1-\mu) k r]+2 t(1-t) f^{\prime \prime}\left(k_{1}\right)\left[\left(\frac{\partial k_{1}}{\partial t_{1}}\right)^{2}+\left(\frac{\partial k_{2}}{\partial t_{1}}\right)^{2}\right]-t[\pi+(1-\mu) k r]\left(\alpha_{1} \frac{\partial k_{1}}{\partial t_{1}}+\alpha_{2} \frac{\partial k_{2}}{\partial t_{1}}\right)}
$$

Proof: See the appendix.

The main difference between a cooperative formula apportionment and a formula apportionment implemented by the local governments is that the cooperative formula apportionment can internalize the negative externality created by the tax competition. In deriving equation result 5, we used such way of internalization that marginal utility from the public good in region 1 is equal to marginal utility from the public good in region 2 . By comparing $\gamma^{k}$ in equation result 4 with $\gamma^{\text {coop }}$ in equation result 5 , we obtain the following condition.

Result 6: $\operatorname{MRS}_{F A}^{\text {local }}>\mathrm{MRS}_{F A}^{\text {coop }}$.

Proof: See the appendix.

Since the cooperative formula apportionment internalizes the negative externality, $\operatorname{MRS}_{F A}^{\text {coop }}$ is smaller than MRS ${ }_{F A}^{\text {local }}$. Result 6 does not provide any information whether the equilibrium tax rate is efficient or not. But, by the same line of reasoning used in section 3.1, if $\mathrm{MRS}_{F A}^{\text {coop }}>1$, then $\mathrm{MRS}_{F A}^{\text {local }}>1$. This relationship states that if tax rates are inefficiently under a cooperative formula apportionment, then the distortion will be more important under a formula apportionment managed by local state government. The formula apportionment is a vehicle through which local governments and multi state firm interact with each other. As a result, the cooperative formula apportionment constitutes a 
welfare improvement for the economy as a whole since result 6 is always satisfied in the symmetric equilibrium. The negative externality due to tax competition between local governments is mitigated under the cooperative formula apportionment. There is welfare loss in the formula apportionment by the local government compared with the cooperative formula apportionment.

\section{Conclusion}

The implementation of a formula apportionment introduces very complicated incentive effects for firms that operate in different jurisdictions and local governments that determine the corporate tax rates. In this paper, we consider a tax competition model with respect to corporate profit taxes under formula apportionment. We show that in a symmetric equilibrium, the tax rate is inefficiently low due to the strategic interaction between local governments.

However, we also show that the degree of inefficiency is less severe when the formula relies on output shares. This result holds because capital responsiveness to changes in tax rates is lower under a formula that exclusively considers the sales shares compared to one that only weighs capital shares. The current shift toward a formula apportionment that gives more importance to the sales shares brings the state corporate income tax closer to a sales tax. We can then argue that the recent shift by most states in the U.S. to a formula apportionment that employs sales shares may constitute an improvement in terms of welfare.

But, there is still a distortion due to tax competition between state governments. The distortion takes the form of lower equilibrium tax rates compared to the tax rates 
under a cooperative formula apportionment. As our findings show, a cooperative formula apportionment mitigate the negative externalities created by tax competition at the local level. 


\section{Appendix}

\section{Proof for Result 4}

$\operatorname{MRS}_{F A}^{k}=\theta \gamma^{k}>\operatorname{MRS}_{F A}^{f}=\theta \gamma^{f}$

Since MRS is affected by the absolute value of $\frac{\partial k_{1}}{\partial t_{1}}$ and $\frac{\partial k_{2}}{\partial t_{1}}$, the proof starts from the comparison between reactions of the multi-state firm under output share formula apportionment and reactions of the multi-state firm under capital share formula

apportionment. Let $\left.\frac{\partial k_{1}}{\partial t_{1}}\right|^{k}$ be the reaction under capital share and $\left.\frac{\partial k_{1}}{\partial t_{1}}\right|^{f}$ be the reaction under output share. To compare them, we denote $\alpha^{k}\left(k_{1}, k_{2}\right)$ under capital shares and $\alpha^{f}\left(k_{1}, k_{2}\right)$ under output shares. At a symmetric equilibrium,

$$
\begin{aligned}
& \alpha^{k}\left(k_{1}, k_{2}\right)=\frac{k_{1}}{k}=\frac{1}{2} \text { and } \alpha_{1}^{k}\left(k_{1}, k_{2}\right)=\frac{k_{2}}{k^{2}}=\frac{k}{2 k^{2}}=\frac{1}{2 k} \\
& \alpha^{f}\left(k_{1}, k_{2}\right)=\frac{f\left(k_{1}\right)}{f\left(k_{1}\right)+f\left(k_{2}\right)}=\frac{1}{2} \text { and } \alpha_{1}^{f}\left(k_{1}, k_{2}\right)=\frac{f^{\prime}\left(k_{1}\right) f\left(k_{2}\right)}{\left[f\left(k_{1}\right)+f\left(k_{2}\right)\right]^{2}}=\frac{f^{\prime}\left(k_{1}\right)}{4 f\left(k_{1}\right)} .
\end{aligned}
$$

Due to the property of concave production function which is identical across the region, the relationship $f^{\prime}\left(k_{1}\right) k_{1}<f\left(k_{1}\right)$ is always true. Therefore, we have the following inequality.

$$
\alpha_{1}^{f}\left(k_{1}, k_{2}\right)=\frac{f^{\prime}\left(k_{1}\right)}{4 f\left(k_{1}\right)}<\frac{1}{4 k_{1}}=\alpha_{1}^{k}\left(k_{1}, k_{2}\right)
$$

In absolute value, $\left.\frac{\partial k_{1}}{\partial t_{1}}\right|^{k}=\frac{1}{(1-t) f^{\prime \prime}\left(k_{1}\right)}\left\{\frac{\alpha(1-\mu) r}{(1-t)}+\alpha_{1}^{k}[\pi+(1-\mu) k r]\right\}$ is greater than

$$
\left.\frac{\partial k_{1}}{\partial t_{1}}\right|^{f}=\frac{1}{(1-t) f^{\prime \prime}\left(k_{1}\right)}\left\{\frac{\alpha(1-\mu) r}{(1-t)}+\alpha_{1}^{f}[\pi+(1-\mu) k r]\right\}
$$

Similarly, due to $f^{\prime \prime}\left(k_{2}\right)<0$ and following inequality holds in absolute value. 


$$
\alpha_{2}^{k}\left(k_{1}, k_{2}\right)>\alpha_{2}^{f}\left(k_{1}, k_{2}\right) \text { in }
$$

where $\alpha_{2}^{k}\left(k_{1}, k_{2}\right)=-\frac{1}{4 k_{2}}$ and $\alpha_{2}^{f}\left(k_{1}, k_{2}\right)=\frac{-f\left(k_{1}\right) f^{\prime}\left(k_{2}\right)}{\left[f\left(k_{1}\right)+f\left(k_{2}\right)\right]^{2}}=\frac{-f^{\prime}\left(k_{2}\right)}{4 f\left(k_{2}\right)}$

$\left.\frac{\partial k_{2}}{\partial t_{1}}\right|^{k}=\frac{1}{(1-t) f^{\prime \prime}\left(k_{2}\right)}\left\{\frac{\alpha(1-\mu) r}{(1-t)}+\alpha_{2}^{k}[\pi+(1-\mu) k r]\right\}$ is also greater than

$\left.\frac{\partial k_{2}}{\partial t_{1}}\right|^{f}=\frac{1}{(1-t) f^{\prime \prime}\left(k_{2}\right)}\left\{\frac{\alpha(1-\mu) r}{(1-t)}+\alpha_{2}^{f}[\pi+(1-\mu) k r]\right.$, when $\frac{\partial k_{2}}{\partial t_{1}}$ is positive.

Then, $\operatorname{MRS}_{F A}^{k}>\operatorname{MRS}_{F A}^{f}$.

\section{Proof for result 5}

Using implicit function theorem, by taking derivative of $\mathrm{U}\left(g_{1}, x_{1}\right)+\mathrm{U}\left(g_{2}, x_{2}\right)$ with

respect to $t_{1}$,

$U_{g_{1}} \frac{\partial g_{1}}{\partial t_{1}}+U_{g_{2}} \frac{\partial g_{2}}{\partial t_{1}}+U_{x_{1}} \frac{\partial x_{1}}{\partial t_{1}}+U_{x_{2}} \frac{\partial x_{2}}{\partial t_{1}}=0$

We assume that in a cooperative formula apportionment a public good is allocated based on the rule by which marginal utility from the public good in region 1 is equal to marginal utility from the public good in region 2 . The first order condition is reduced to

$U_{g_{1}}\left(\frac{\partial g_{1}}{\partial t_{1}}+\frac{\partial g_{2}}{\partial t_{1}}\right)+U_{x_{1}} \frac{\partial x_{1}}{\partial t_{1}}+U_{x_{2}} \frac{\partial x_{2}}{\partial t_{1}}=0$

At the symmetric equilibrium,

$$
\begin{aligned}
& \frac{\partial x_{1}}{\partial t_{1}}=-\theta \alpha\left(k_{1}, k_{2}\right)[\pi+(1-\mu) k r] \\
& \begin{aligned}
\frac{\partial g_{1}}{\partial t_{1}}+\frac{\partial g_{2}}{\partial t_{1}}= & \left\{\alpha\left(k_{1}, k_{2}\right)[\pi+(1-\mu) k r]+2 t(1-t) f^{\prime \prime}\left(k_{1}\right)\left[\left(\frac{\partial k_{1}}{\partial t_{1}}\right)^{2}+\left(\frac{\partial k_{2}}{\partial t_{1}}\right)^{2}\right]\right\} \\
& -t \alpha_{1}\left(k_{1}, k_{2}\right)[\pi+(1-\mu) k r] \frac{\partial k_{1}}{\partial t_{1}}-t \alpha_{2}\left(k_{1}, k_{2}\right)[\pi+(1-\mu) r] \frac{\partial k_{2}}{\partial t_{1}}
\end{aligned}
\end{aligned}
$$


Then, MRS of region 1 under a cooperative formula apportionment, when marginal utility from the public good in region 1 is equal to marginal utility from the public good in region 2 is

$$
\text { MRS }=\frac{\frac{\partial x_{1}}{\partial t_{1}}}{\frac{\partial g_{1}}{\partial t_{1}}+\frac{\partial g_{2}}{\partial t_{1}}}
$$

\section{Proof of Result 6}

3RS $_{F A}^{\text {local }}>$ MRS $_{F A}^{\text {coop }}$ if and only if

$\frac{\frac{1}{2} \theta[\pi+(1-\mu) k r]}{\frac{1}{2}[\pi+(1-\mu) k r]+t(1-t) f^{\prime \prime}\left(k_{1}\right)\left[\left(\frac{\partial k_{1}}{\partial t_{1}}\right)^{2}+\left(\frac{\partial k_{2}}{\partial t_{1}}\right)^{2}\right]}>$

$\frac{\theta \frac{1}{2}[\pi+(1-\mu) k r]}{\frac{1}{2}[\pi+(1-\mu) k r]+2 t(1-t) f^{\prime \prime}\left(k_{1}\right)\left[\left(\frac{\partial k_{1}}{\partial t_{1}}\right)^{2}+\left(\frac{\partial k_{2}}{\partial t_{1}}\right)^{2}\right]-t[\pi+(1-\mu) k r]\left(\alpha_{1} \frac{\partial k_{1}}{\partial t_{1}}+\alpha_{2} \frac{\partial k_{2}}{\partial t_{1}}\right)}$

which is reduced to $(1-t) f^{\prime \prime}\left(k_{1}\right)\left[\left(\frac{\partial k_{1}}{\partial t_{1}}\right)^{2}+\left(\frac{\partial k_{2}}{\partial t_{1}}\right)^{2}\right]>[\pi+(1-\mu) k r]\left(\alpha_{1} \frac{\partial k_{1}}{\partial t_{1}}+\alpha_{2} \frac{\partial k_{2}}{\partial t_{1}}\right)$

By rearranging the inequality,

$\left(\frac{\partial k_{1}}{\partial t_{1}}\right)^{2}+\left(\frac{\partial k_{2}}{\partial t_{1}}\right)^{2}<\frac{[\pi+(1-\mu) k r]}{(1-t) f^{\prime \prime}\left(k_{1}\right)}\left(\alpha_{1} \frac{\partial k_{1}}{\partial t_{1}}+\alpha_{2} \frac{\partial k_{2}}{\partial t_{1}}\right)$

From equation (1) and (2)

$$
\begin{aligned}
& \frac{\partial k_{1}}{\partial t_{1}}-\frac{1}{(1-t) f^{\prime \prime}\left(k_{1}\right)} \frac{\alpha(1-\mu) r}{(1-t)}=\alpha_{1} \frac{[\pi+(1-\mu) k r]}{(1-t) f^{\prime \prime}\left(k_{1}\right)}, \\
& \frac{\partial k_{2}}{\partial t_{1}}-\frac{1}{(1-t) f^{\prime \prime}\left(k_{2}\right)} \frac{\alpha(1-\mu) r}{(1-t)}=\alpha_{2} \frac{[\pi+(1-\mu) k r]}{(1-t) f^{\prime \prime}\left(k_{1}\right)}
\end{aligned}
$$


Then, the inequality is transformed into,

$$
\begin{aligned}
& \left(\frac{\partial k_{1}}{\partial t_{1}}\right)^{2}+\left(\frac{\partial k_{2}}{\partial t_{1}}\right)^{2}< \\
& \left(\frac{\partial k_{1}}{\partial t_{1}}-\frac{1}{(1-t) f^{\prime \prime}\left(k_{1}\right)} \frac{\alpha(1-\mu) r}{(1-t)}\right) \frac{\partial k_{1}}{\partial t_{1}}+\left(\frac{\partial k_{2}}{\partial t_{1}}-\frac{1}{(1-t) f^{\prime \prime}\left(k_{2}\right)} \frac{\alpha(1-\mu) r}{(1-t)}\right) \frac{\partial k_{2}}{\partial t_{1}} \text { and }
\end{aligned}
$$

the inequality is simplified again as

$$
\begin{aligned}
& 0<-\frac{1}{(1-t) f^{\prime \prime}\left(k_{1}\right)} \frac{\alpha(1-\mu) r}{(1-t)}\left(\frac{\partial k_{1}}{\partial t_{1}}+\frac{\partial k_{2}}{\partial t_{1}}\right) . \\
& \text { Since } \frac{\partial k_{1}}{\partial t_{1}}+\frac{\partial k_{2}}{\partial t_{1}}=\frac{1}{(1-t) f^{\prime \prime}\left(k_{1}\right)} \frac{\alpha(1-\mu) r}{(1-t)}+\alpha_{1} \frac{[\pi+(1-\mu) k r]}{(1-t) f^{\prime \prime}\left(k_{1}\right)} \\
& +\frac{1}{(1-t) f^{\prime \prime}\left(k_{2}\right)} \frac{\alpha(1-\mu) r}{(1-t)}+\alpha_{2} \frac{[\pi+(1-\mu) k r]}{(1-t) f^{\prime \prime}\left(k_{1}\right)}=\frac{2}{(1-t) f^{\prime \prime}\left(k_{1}\right)} \frac{\alpha(1-\mu) r}{(1-t)}<0, \\
& 0<-\frac{1}{(1-t) f^{\prime \prime}\left(k_{1}\right)} \frac{\alpha(1-\mu) r}{(1-t)}\left(\frac{\partial k_{1}}{\partial t_{1}}+\frac{\partial k_{2}}{\partial t_{1}}\right) \text { is always true. }
\end{aligned}
$$




\section{Table 1}

\section{STATE APPORTIONMENT OF CORPORATE INCOME}

(Formulas for tax year 2004 -- as of January 1, 2004)

ALABAMA *
ALASKA *
ARIZONA *
ARKANSAS *
CALIFORNIA *
COLORADO *
CONNECTICUT
DELAWARE
FLORIDA
GEORGIA
HAWAII *
IDAHO *
ILLINOIS *
INDIANA
IOWA
KANSAS *
KENTUCKY *
LOUISIANA
MAINE *
MARYLAND
MASSACHUSETTS
MICHIGAN
MINNESOTA
MISSISSIPPI
MISSOURI *
MONTANA *

3 Factor
3 Factor
Double wtd. Sales
Double wtd. Sales
Double wtd. Sales
3 Factor/Sales \& Property
Double wtd. sales/Sales
3 Factor
Double wtd. sales
Double wtd. sales
3 Factor
Double wtd. sales
Sales
Double wtd. sales
Sales
3 Factor
Double wtd. sales
Double wtd. sales
Double wtd. sales
Double wtd. sales
Double wtd. sales/Sales
90\% Sales, 5\% Property
\& Payroll
$75 \%$ Sales, 12.5\% Property,
and $12.5 \%$ Payroll
Accounting/3 Factor
3 Factor/sales
3 Factor

NEBRASKA

NEVADA

NEW HAMPSHIRE

NEW JERSEY (1)

NEW MEXICO *

NEW YORK

NORTH CAROLINA*

NORTH DAKOTA *

$\mathrm{OHIO} *$

OKLAHOMA

OREGON *

PENNSYLVANIA *

RHODE ISLAND (2)

SOUTH CAROLINA

SOUTH DAKOTA

TENNESSEE *

TEXAS

UTAH *

VERMONT

VIRGINIA

WASHINGTON

WEST VIRGINIA *

WISCONSIN *

WYOMING

DIST. OF COLUMBI
Sales

No State Income Tax Double wtd. Sales

Double wtd. Sales

Double wtd. sales

Double wtd sales

Double wtd. sales 3 Factor

$60 \%$ Sales, 20\% Property

$\&$ Payroll

3 Factor

$80 \%$ Sales, $10 \%$ Property $\&$ Payroll

Triple wtd. sales

40\% Sales, 30\% Property $\&$ Payroll

Double wtd. sales/Sales

No State Income Tax

Double wtd. sales

Sales

3 Factor

3 Factor

Double wtd. sales

No State Income Tax

Double wtd. sales

Double wtd. sales

No State Income Tax 3 Factor

Source: Compiled by FTA from various sources.

Note: The formulas listed are for general manufacturing businesses. Some industries have special formula different than those reported.

* State has adopted substantial portions of the UDITPA.

(1) A 3-factor formula is used for corporations not subject to the corporation business franchise tax.

(2) For tax years beginning after 2004, apportionment formula will be double weighted sales 


\section{Chapter 5}

\section{Conclusion}




\section{Conclusion}

In this chapter, I briefly summarize and conclude the contribution of the dissertation to the related literature.

\subsection{Collusion, Political Control and Discretion}

In this paper, we examine the conditions under which corruption is observed either at the bureaucratic or legislative level. When the political cost is high enough and monitoring is very effective, a no-collusion state is likely to be achieved because the high political cost disciplines the politician and the efficient monitoring precludes the bureaucrat from engaging in a collusive behavior with the firm. However, when the political cost is low, high monitoring only disciplines the bureaucrat, and opens an opportunity for the politician and firm to collude with each other. According to our model, the political cost parameter plays a critical role in preventing collusion.

In a politician's initiative regime, the politician decides whether to monitor bureaucrat or not. The politician exerts an effort to allow pollution if the transfer to the politician in the first stage of the game outweighs the expected payoffs earned by monitoring in the second stage of the game. If the transfer to the politician in the first stage of the game is smaller than the expected payoffs in the second stage, the politician never colludes with the firm in the first stage. No political collusion is achieved at the expense of a social cost determined by the amount resources that are required to compensate the politician. With a high monitoring cost, the politician gives up monitoring, leading to bureaucratic collusion.

In a voter's initiative regime, the voter decides the level of monitoring on bureaucrats and political cost. No collusion can be obtained by choosing the level of 
monitoring and political control appropriately relative to the level of deregulation benefits. Even in this regime, we cannot exclude the possibility of collusion. If the monitoring and political costs are very high, the optimal levels of political pressure and monitoring become zero, going back to the situation of bureaucratic or political collusion. A no-collusion state is an exceptional social phenomenon according to our model. The two stages model captures the whole process of policy making and implementation and sheds new insight on corruption in the political and administrative sectors.

\subsection{Policy Preferences on Policy Outcome with an Incompletely Informed Politician}

When the upper middle class and the lower middle class articulate the same political messages to the policymaker, the middle class obtains its ideal policy if it pursues a moderate policy change from the current status quo. There exists a pooling equilibrium which supports a policy change toward the ideal policy of the middle class. This pooling equilibrium is robust in the sense that even if the differences between political power are significant, an equilibrium which benefits the middle class exists. In the case of an important policy change, a conflict of interest between the upper and lower middle class may arise. This conflict is avoided if the ideal policies of the two subgroups are very close.

A separating equilibrium where the ideal policies of the upper middle class are adopted exists if the differences in political power between social groups are small. It is interesting to note that in a separating equilibrium as the proportion of the upper middle class increases and ideal policies between subgroups within middle class diverge, the probability of rejecting the proposal of the lower middle increases. If the policy change is 
substantial, a separating equilibrium is not robust, it may increase the divergence within the middle class, and weaken the political power of the middle class. Policy transition toward $x_{h}^{\prime}$ or $x_{l}^{\prime}$ is unconditionally supported by the rich or the poor. According to our model, the middle class achieves its ideal policy through the internal allegiance and outside support from the poor or the rich. But, the degree of policy change should be moderate, because drastic policy changes may generate a conflict of interests within the middle class.

\subsection{Apportionment Formula and Strategic Competition}

The implementation of a formula apportionment introduces very complicated incentive effects for firms that operate in different jurisdictions and local governments that determine the corporate tax rates. In this paper, we consider a tax competition model with respect to corporate profit taxes under formula apportionment. We show that in a symmetric equilibrium, the tax rate is inefficiently low due to the strategic interaction between local governments. However, we also show that the degree of inefficiency is less severe when the formula relies on output shares. This result holds because capital responsiveness to changes in tax rates is lower under a formula that exclusively considers the sales shares compared to one that only weighs capital shares.

The current shift toward a formula apportionment that gives more importance to sales shares brings the state corporate income tax closer to a sales tax. We can then argue that the recent shift by most states in the U.S. to a formula apportionment that employs sales shares may constitute an improvement in terms of welfare. However, there is still a distortion due to tax competition between state governments. The distortion takes the form of lower equilibrium tax rates compared to the tax rates chosen by a federal 
government. As our findings show, a formula apportionment implemented by the federal government may weaken the negative externalities created by tax competition at the local level. 


\section{References}

Acemoglu, D and Verdier, T (1998), "Property rights, corruption and the allocation of talent: a general equilibrium approach”, Economic Journal, volume 108, pp. 1381-1403. Alesina, A and Tabellini G (2003), “Bureaucrats or Politicians?”, Mimeo

Anand, B. N., and R. Sansing (2000), “The Weighting Game: Formula Apportionment as an Instrument of Public Policy,” National Tax Journal, 53(2).

Austen-Smith, David. (1993), “Information and Influence: Lobbying for Agendas and Votes,” American Journal of Political Science 37: 799-833.

Banks, J and Weingast, B., (1992) “The Political Control of Bureaucracies under Asymmetric Information,” American Journal of Political Science 37: 799-833.

Boadway, Robin and Motohiro (2003), “A model of interactions between politicians and Bureaucrats,” Mimeo.

Boyer, Marcel and Laffont, Jean Jacques (1999), “Toward a Political Theory of the Emergence of Environmental Incentive Regulation,” RAND Journal of Economics, Vol. 30, No. 1 pp137-157.

Börner, Kira (2004), “Political Economy Reasons for Government Inertia: The Role of Interest Groups in the Case of Access to Medicines,” Discussion paper 2004-4, Department of Economics, University of Munich.

Breton, Albert, and Wintrobe, Ronald, (1982), "The Logic of Bureaucratic Control,” Cambridge: Cambridge University Press.

Buchanan, James M. and Tullock, Gordon, (1962), “The Calculus of Consent: Logical Foundations of Constitutional Democracy,” Ann Arbor: University of Michigan Calvert, R., McCubbins, M and Weingast, B., (1989) “A Theory of Political Control and 
Agency Discretion,” American Journal of Political Science 33: 588-611.

Dhami, Sanjit (2003), “The political economy of redistribution under asymmetric Information,” Journal of Public Economics 87, 2069-2103.

Dixit, A and Londregan, John (1998), "Ideology, Tactics, and Efficiency in Redistributive Politics,” Quarterly Journal of Economics, 497-529

Downs Anthony, (1957), “An Economic Theory of Democracy,” New York: Harper Collins Publishers, Inc.

Edmiston, Kelly D. (2002), "Strategic Apportionment of the State Corporate Income Tax," National Tax Journal, 55(2), 239-262.

Edwards, C (2004), “State Corporate Income Taxes Should Be Repealed,” Cato Institute No. 19.

Eskeland, Gunnar S and Thiele, Henrik (1999), “Optimal corruption under moral hazard,” Mimeo.

Pethig, R and Wagener, A (2003), "Profit Tax Competition and Formula Apportionment,” Mimeo.

Fujimura, Masayuki (2000), "The Welfare State, the Middle Class, and the Welfare Society,” Review of Population and Social Policy, No. 9, 1-23.

Gavious, A and Shlomo (2003), “A signaling model of peaceful political change,” Social Choice and Welfare 20: 119-136.

Goolsbee, A., and E. L. Maydew (2000), “Coveting Thy Neighbor’s Manufacturing: the Dilemma of State Income Apportionment,” Journal of Public Economics, vol. 75(1), pp. $125-143$.

Gordon, R. H., and J. D. Wilson (1986), “An examination of multijurisdictional corporate 
income taxation under formula apportionment,” Econometrica, 54(6), 1357-73.

Gromb and Scharfstein, Davis (2002), “Entrepreneurship in Equilibrium”, Mimeo.

Grossman and Helpman (2001), “Special Interest Politics,” MIT Press

Jones, P, (1978), “The Appeal of the Political Entrepreneur,” British Journal of Political

Science, 8(4), 498-504.

Kaufmann, Daniel (1998), “Revisiting Anti-Corruption Strategies: Tilt Towards

Incentive-Driven Approaches?,” United Nations Publications.

Lohmann, Susanne. (1993), “A Signaling Model of Informative and Manipulative

Political Action,” American Political Science Review 87: 319-333.

Lohmann, Susanne. (1995) “Information, access, and contributions: A signaling

model of lobbying,” Public Choice 85: 267-284.

Marjit, S and Shi, Heling (1998), “On controlling crime with corrupt officials,” Journal of

Economic Behavior and Organization.

McClure, C. E. (1980), “The state corporate income tax: lambs in wolves clothing?,” In:

Aaron, H. J., and M. Boskin (Eds), The Economics of Taxation, The Brookings

Institution, Washington, DC.

McClure, C. E. (1981), "The elusive incidence of the corporate income tax: the state

Case,” Public Finance Quarterly, 9(4), 395-413.

Mookherjee, D and Png, I (1994), "Corruptible law enforcers: how should they be compensated?, " Economic Journal, volume 104, pp. 145-159.

Mule, Rosa (2001), “Political Parties, Games and Redistribution,” Cambridge University Press.

Nielsen, Pascalis and Guttorm (2000), “Formula Apportionment and Transfer Pricing 
under Oligopolistic Competition,” Working paper 2000.

Niskanen, W. A. (1971), “Bureaucracy and representative government”, Chicago:Aldine. Niskanen, W. A. (1975), “ Bureaucrats and Politicians Journal of Law and Economics,” 18, 618-643.

Olson Mancur, (1971), “The Logic of Collective Action: Public Goods and the Theory of Groups,” Harvard University Press, Cambridge, Mass.

Potters, Jan, and Winden, Frans Van (1992). "Lobbying and asymmetric information,” Public Choice, 74: 269-292.

Randall L. Calvert; Mathew D. McCubbins; Barry R. Weingast, “A Theory of Political Control and Agencey Discretion,” American Journal of Political Science, pp. 588-611. Sloof, Randolph, and Winden, Frans Van (2000), “Show them your teeth first! A gametheoretic analysis of lobbying and pressure,” Public Choice, 104: 81-120. Stigler, George, (1970) “Director’s Law of Public Income Redistribution.” Journal of Law and Economics, XIII, 1-10.

Stigler, George, (1971), “The Theory of Economic Regulation,” Bell Journal of Economics, 2, 3-21.

Transparency International (2003), “The Transparency International Global Corruption Barometer 2003,” PRESS RELEASE.

Weingast, B and Shepsle, Johnsen, C (1981), "The political economy of benefits and costs: A Neoclassical Approach to Distributive Politics,” Journal of Political Economy, 642-664. 